مجلة جامعة الدلك عبدالعزيز: الآداب والعلوم الانسانية، م21، ص ص: 127-162 (2013م/1434هـ) DOI:10.4197 / Art.20-4

دور برامج التأهيل في التوعية بالتخطيط للزواج وبناء الأسرة "دراسة وصفية تحليلية لبرامج التأهيل للزواج والمستفيدين منها * بمدينة جدة"

عبيد علي عطيان آل مظف و غيداء عبد الله الجويسر

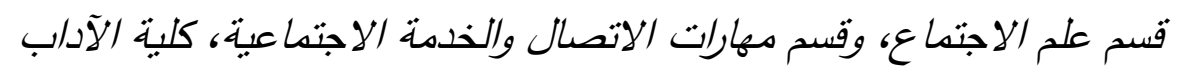

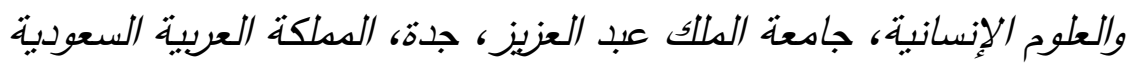

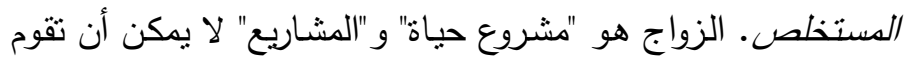

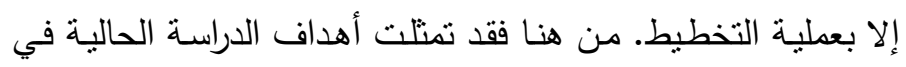

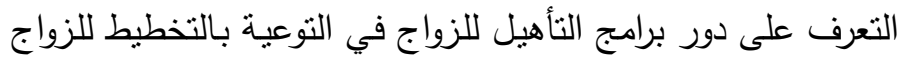

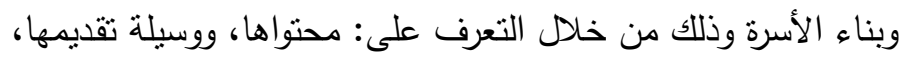

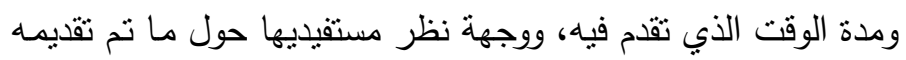

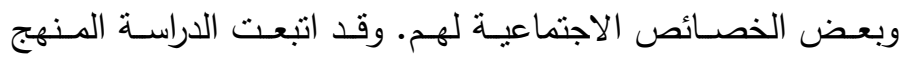

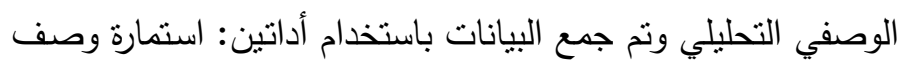

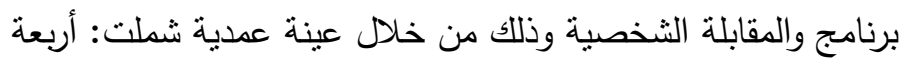

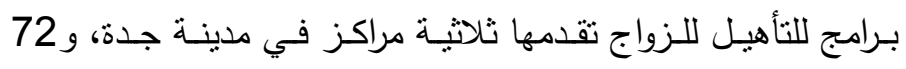

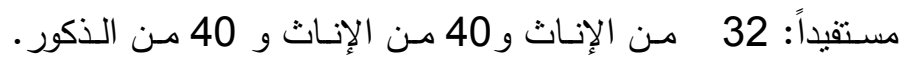

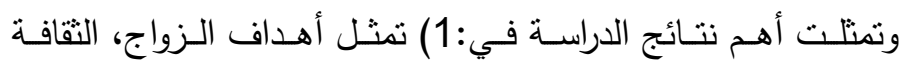

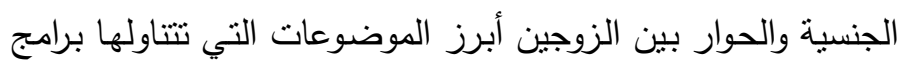


التأهيل للزواج. 2) تميل البرامج إلى إتباع أسلوب العرض النظري

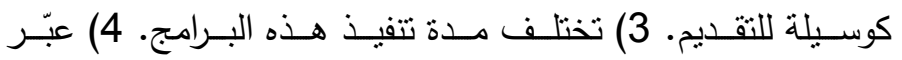
المستفيدون عن درجة أعلى من الرضى حول مقدمي البرامج ووسائل

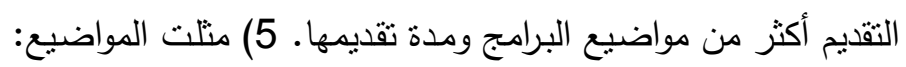

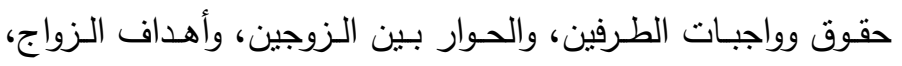

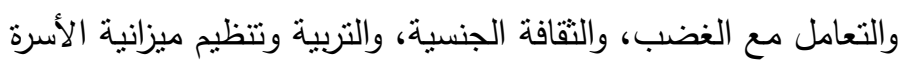

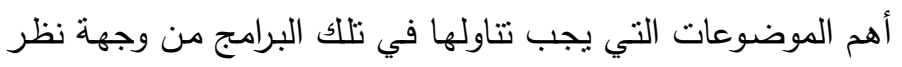

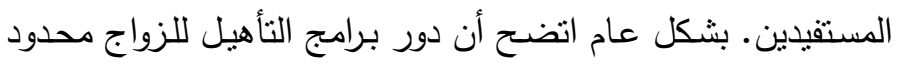

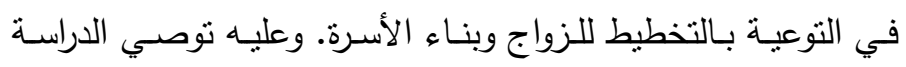

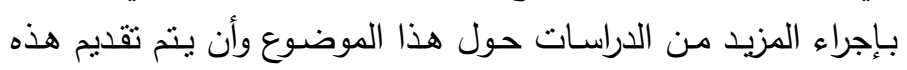

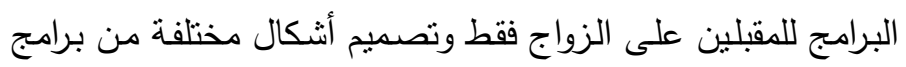

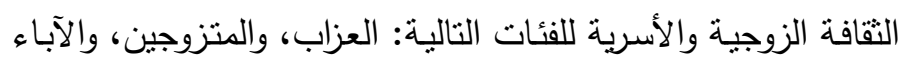
والأمهات، والمطلقين، والأرامل.

\section{المقدمـة}

يـرتبط نجـاح الفـرد بأدائـه الصـحيح لـدوره الاجتمـاعي، وهـا الأداء يتطلب مـن الإنسان أن يمنلك مهارات معينة، تساعده على شخل دوره. وحين يتخذ الفرد قرار الزواج، فإنه يستعد لاكتساب دور اجتماعي جديد في حياته، فقد كان بالأمس ابنا وسيصبح في الغد زوجاً، وبعد ذلك بفترة، سيصبح أباً، وتستمر دورته في اكتساب

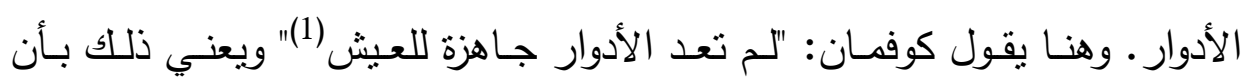
تحمل مسؤوليات الأدوار في الزمن الحاضر لم يعد سهـلاً كما كان، وهنـا تقول ماريـا كيفالاس: "في السنوات السـابقة كـان زواج الإنسـان دليلاً على أنـه أصبح

(1) ج. ك. كوفمان، علم اجتماى الثنائي، ترجمة بسمة بدران، بيروت، المؤسسة الجامعية

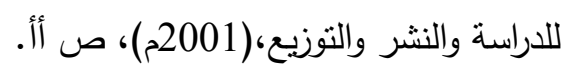


ناضجًا أما اليوم فإن الإنسان لابد أن يصبح ناضجًا كي يتزوج(1)". والزواج هو

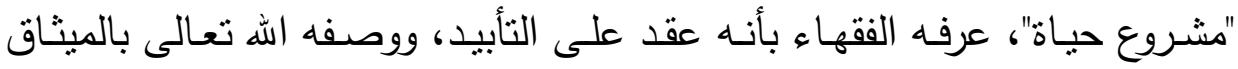

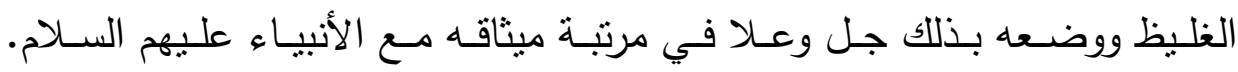

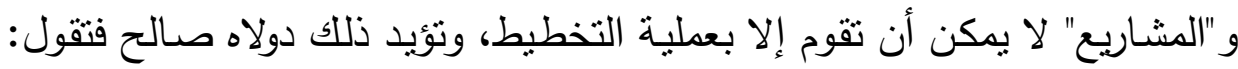
"نحن مجتمع ينفق الكثير والكثير في النخطيط للزفاف أكثر مما ينفق في التخطيط

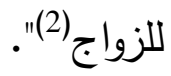

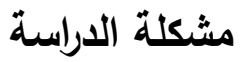

بلغت نسبة المشكلات الأسرية والزوجية 50٪ من مجموع المشكلات الواردة

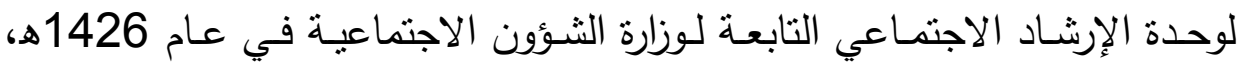

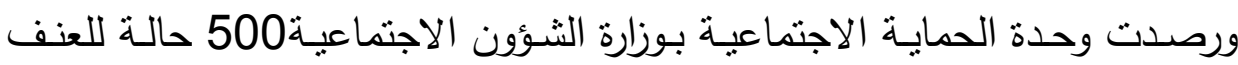

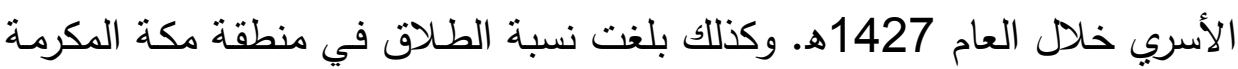
30 \% في عام 1428هـ.

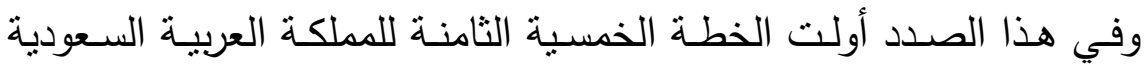

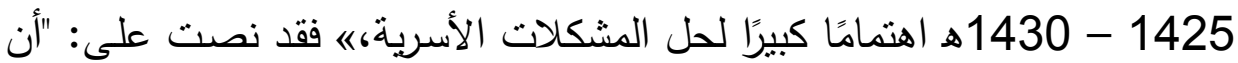
ما تتعرض إليه الأسرة من ضغوط ومؤثرات، وما تواجهه من متتكلات وتحديات، تهدد استمرار فاعليتها المجتمعية، وتكاد تعصف بدورها، فالعنف والطلاق والتفكلك

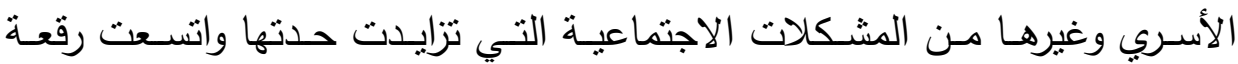
انتشـارها في الحقبة الأخيرة على مستوى العالم، جعل من قضـايا حماية الأسرة

Maria Kefalas, Marriage is more than being together: The meaning of Marriage among young adults in ${ }^{(1)}$ the United States, Network on Translition to Adulthood Research Network (sept, 2005), Working Paper, p. 7.

Dolah Saleh: The Planning of Marriage, the next time someone admonishes you saying that you are "too picky", say "thank you" and appreciate the complement. http://www.dolah.net/docs/love/planningofaMarrige.pdf viewed at 26/1/1430 


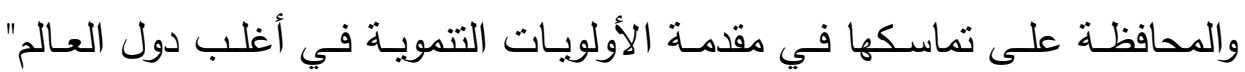
وأضافت الخطة: "أن النظرة التقليدية المحدودة في معالجة قضايا الأسرة وآفاقها وتحدياتها، وذلك من خلال حصرها في قطاع واحد كخدمات الرعاية الاجتماعية أو جهة حكومية واحدة كالثؤون الاجتماعية لن تتمكن من الإحاطة بشمولية هذه واله

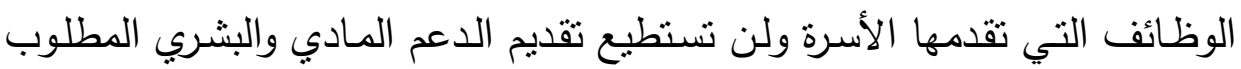
لتمكينها من مواجهة التحديات التتموية القائمة(1) ".

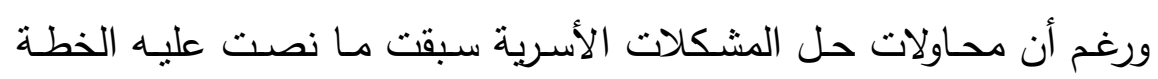

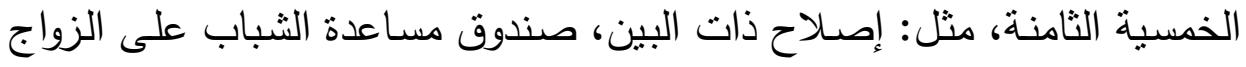

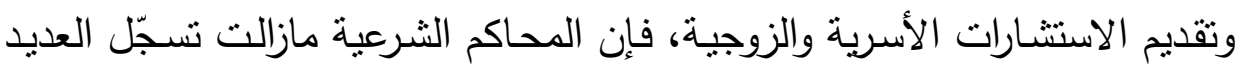

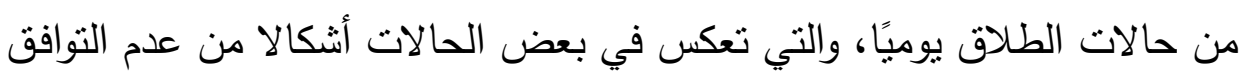

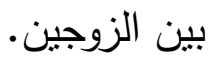

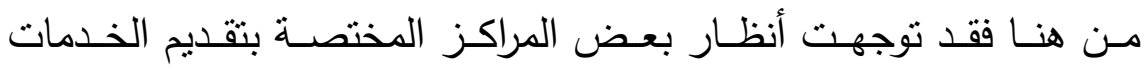

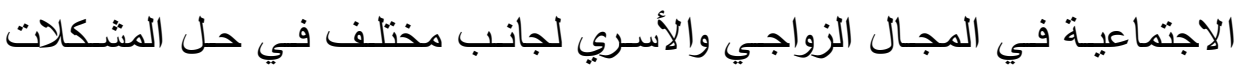

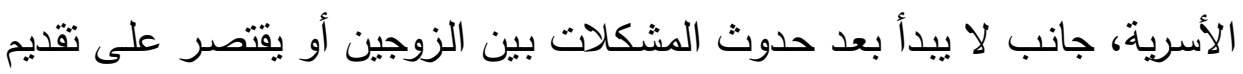

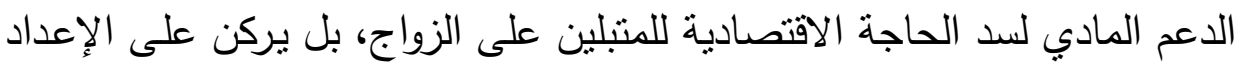

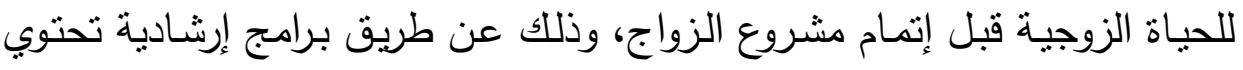
على دورات تدريبية يتم تقديمها للمقبلين على الزواج تحت مسمى "التأهيل للزوراج".

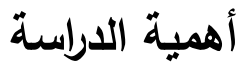

على المستوى النظري تتمثل أهمية الدراسـة في قلـة الدراسـات الاجتماعية التي بحثت في هذا الموضوع - قدر علم الباحثة، على المستوى المحلي مقارنة التحة

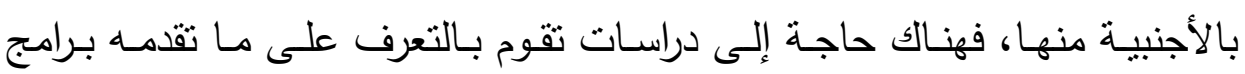

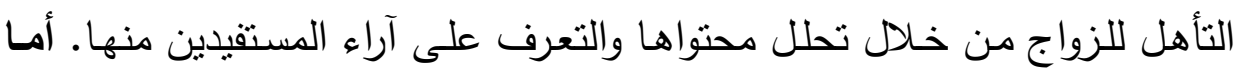

(1) وزارة الاقتصاد والتخطيط، خطة التتمبة الثامنة 1425 - 1430هـ، الرياض: وزارة الاقتصاد والتخطيط، (1429هارة)، صيط: 333 - 334. 
على المستوى التطبيقي فتظهر أهمية الدراسـة في المساهمة في تطوير أهداف

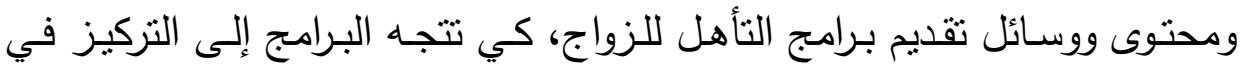

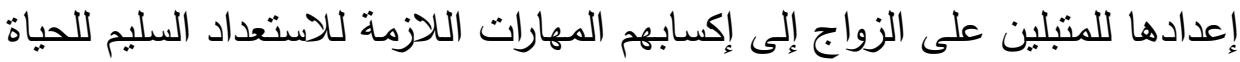

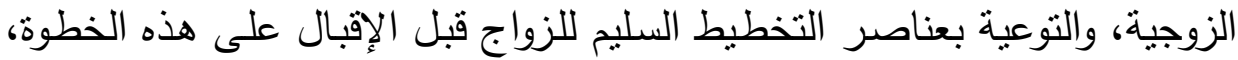

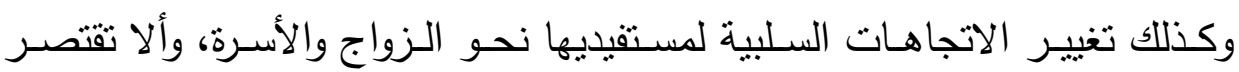
الاستفادة من هذه البرامج على الجانب النظري فقط.

\section{مفاهيم الدراسة}

أ. برامج التأهيل للزواج Marriage Education Program

هي برامج توفر معلومـات مصدمة لمسـاعده المقبلين على الزواج على

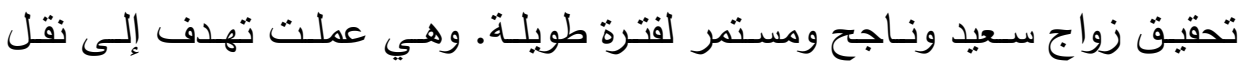
المعرفة ولاتجاهـات وإكساب العمارات والسـوكيات التي تحتاجها العلاقـة الزوجيـة وفية الناجحة والحميمة (1).

المفهوم الإجرائي لبرامج التأهيل للزواج: تقصد الباحثة ببرامج الإرشاد في

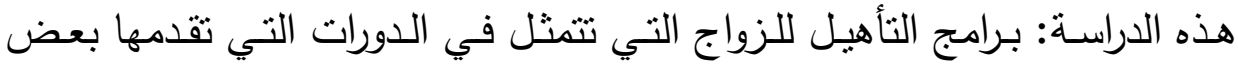
مراكز الإرشـاد الأسـرى والزواجي وبعض الجمعيـات الخيريـة المختصــة بالشـؤون الأسرية وشتى الدورات التي تحث مُسَمَى "التأهيل للزواجئ.

\section{بw. التوعية Awareness}

التوعية هي عملية منظّمة مدروسة تستهدف تغبير اتجاهات وآراء، وأفكار

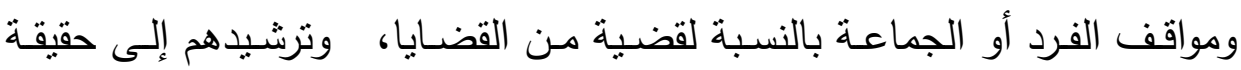

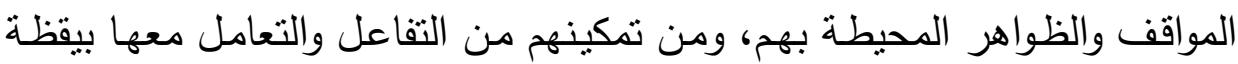


وفهم كاملين (1).

\section{التعريف الإجرائي للتوعية}

نشـر التقافة الزوجيـة، عن طريـق الدورات التدربيـة والمحاضـرات ضــن برنامج إرشـادي متكامل، لتغيير اتجاهات وآراء وأفكار المقبلين على الزواج نحو مسؤولية الـزواج والأسـرة، ليتمكنـوا مـن التعامـل مـع الضـغوط الزوجيـة والأسـرية بمستوى من الإدراك يحقق الاستقرار الزواجي والأسري.

\section{Planning التخطيط}

منهج بتضمن عدة إجراءات لتحقيق غايات أو أهداف مرغوب فيها. ويرى كاول مانهايم بأنه أسلوب للتفكير المنظم يحاول أن يحيط بكل الأحداث التي تسود

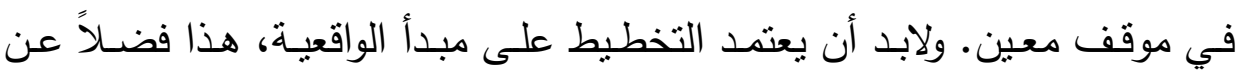
مجموعة مبادئ أخرى أهمها، الاستمرار ، والثمول والتكامل، والمرونة والتتسيق (2). المفهـوم الإجرائسي للتوعيـة بـالتخطيط للـزواج وينـاء الأسـرة الاسـتعداد لمشـروع الـزواج اســتعدادا لا بشــمل فقـــ إعـداد بيــت الزوجيــة والاحتفــالات الاجتماعية، بل تشمل توقعات الحياة الزوجية، التكيف مع ما يحدثه الانتقال لبيت الزوجيـة من تغيرات في نمط الحياة وتحمل المسؤوليات بمـا تشمله مـن الحقوق والواجبات بين الزوجين والتعامل مـع المواقف المختلفة التي تحدث بين الزوجين بطربقة صحيحة، المشاركة بين الزوجين وغيرها من العناصر التي تجعل الرؤية

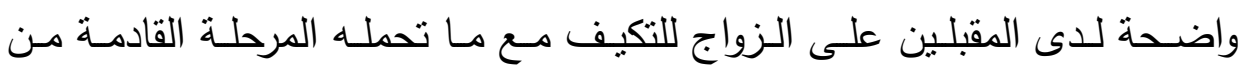

(1) عايد محمد علي القحطاني، مدى فاعلية برامج التوعية ضد أخطار المخدرات دراسة تطبيقية

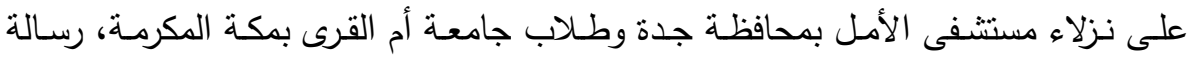

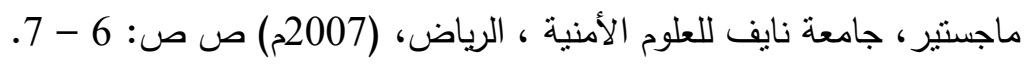

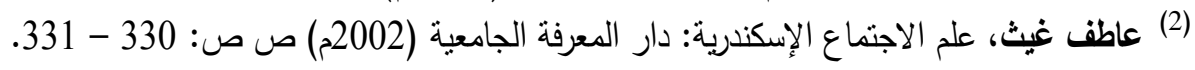


تغيرات.

\section{أهداف الاراسة}

1. التعرف على المواضع المقدمة في برامج التأهيل للزواج ووسائل تقديمها. 2. التعرف على جوانب التشابه والاختلاف بين البرامج المقدمة في مراكز مختلفة تقدم هذه البرامج.

3. التعرف كذلك على العلاقة بين بعض المتغيرات الديموغرافية للمستقيدين وبين وجهه نظرهم تجاه ما تم تقديمه.

\section{تساويلات الارراسة}

1. مـا المواضـع التي تتناولها برامج التأهيل للزواج؟ ومـا الوسـائل المستخدمة في تتفيذها؟ 2. ما جوانب التشابه والاختلاف بين البرامج المقدمة في مراكز مختلفة تقدم هذه البرامج? 3.مـا الخصـائص الاجتماعيـة للمسـتقيدين مـن البرامج في كل مـن: (الجنس، والعمر ، والحالة الاجتماعية، والمستوى التعليمي، والمستوى الاقتصادي)؟

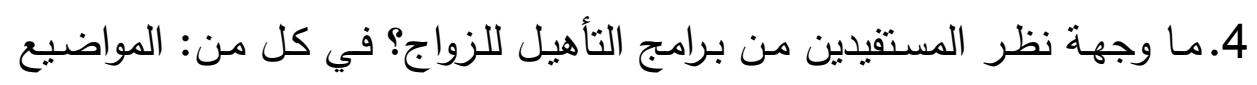
التي تتاولها البرنـامج، مـدد البرامج/الدورات، وسـائل تقديم البرنـامج، مقدمي فئي

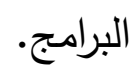

5. مـاذا تحتـاج بـرامج التأهيـل للزواج مـن وجهـه نظـر المسـقفيدين في العناصـر

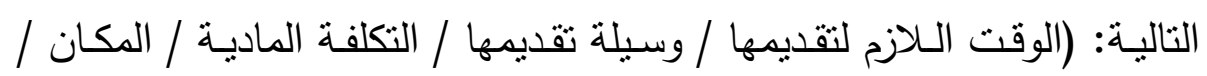
التحفيز للالتحاق بها / مقدميها)؟

6.ما هي المواضيع المهمة من وجهة نظر المستقيدين لتناولها في برامج التأهيل 
الزواج فيمـا يتعلق بـالزواج والأسـرة؟ وهل هنـاك علاقة بين بعض المتغيرات الديموغرافية للمستفيدين وبين وجهة نظرهم تجاه ما تم تقديمه؟ برون

\section{أدبيات الاراسة}

أولا: برامج التأهيل للزواج

أنواعها وأشكالها تختلف أنواع برامج التأهيل للزواج حسب الأهداف التي

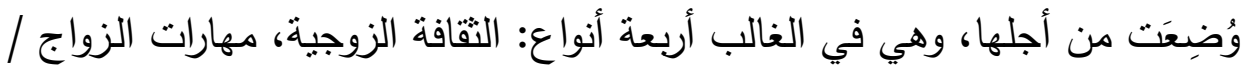

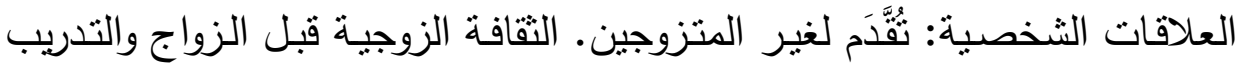
على مهارات الزواج: تُقََّمَ لمن في فترة الخطبة وللعزاب المهتمين بموضوع الزواج.

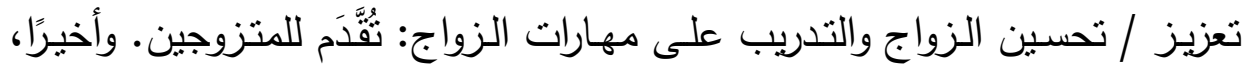
البرامج التي تهدف لخفض معدلات الطلاق والتي تُقََّم للمتزوجين الذين يواجهون

مشكلات زوجية(1).

المواضيع التـي تطرحها ومحتواهـا: يمكن تصنيف المحتوى الذي تقوم

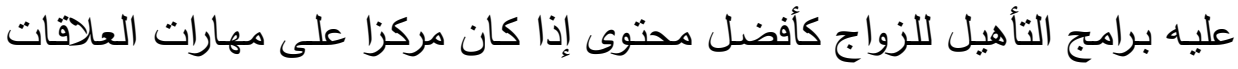

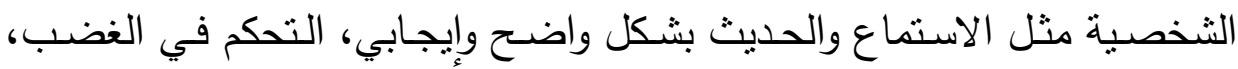
التفاوض والاختلافات وتحويل التفاعل السلبي إلى ايجابي. وتتمنل معايير تصنيف محتوى برامج التأهيل للزوج حسب الأفضل والأقل فعالية في اشتمال محتواها على ولى الثابل العناصر التالية: الاتجاهات، المهارات والسلوكيات اللازمـة للحصول على علاقية زوجية ناجحة والتي يمكن إكسابها للمستقيدين، المرجع العلمي، حجم المجموعات،

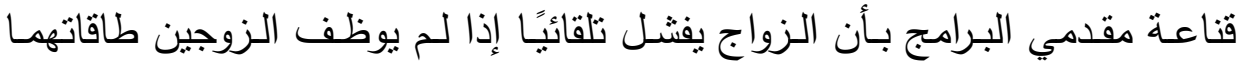
لأجله، ووجوب احترام الرجال والنساء على حد سواء كثريكين متساوبين يتشاركان في اتخاذ القرارات.

وسـائل تقديمها: أمـا فيما يتعلق بوسيلة تقديم هذه البرامج، فنجد بأنها 
تسـتخدم وسـائل تعليميـة منتوعـة هـي مـزبج مـن المحاضـرات النظريـة، التمـارين التدريبية - المُصمَّصة لإكساب مهارات معينة في التواصل والعلاقات الثخصية،

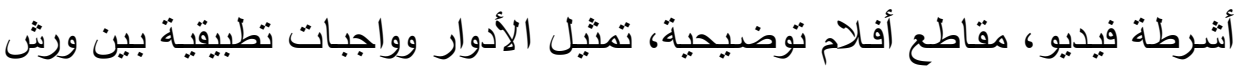
(1) (1) (1)

معيار جودتها: ويتمثل معيار جودة وسيلة تقديم برامج التأهيل للزواج في

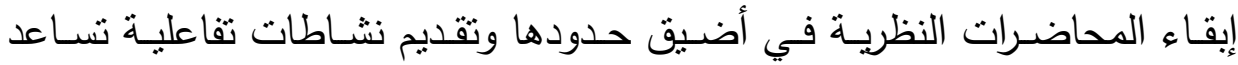
المستقيدين لبناء مهاراتهم. فعلى سبيل المثال تبدأ بعض البرامج بعرض تهاء تقديمي

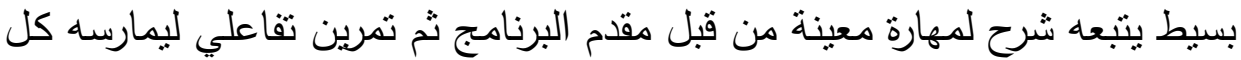

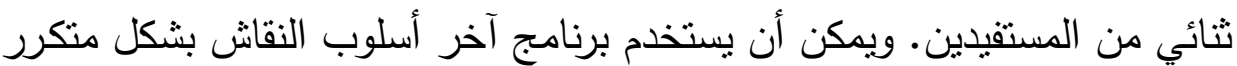

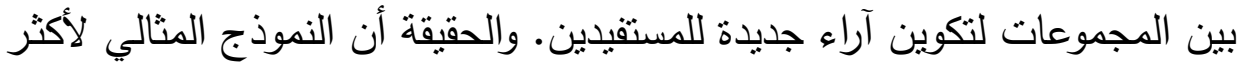
برامج التأهيل للزواج فعالية هو الذي يضم قدرا كبيرًا من المعرفة في محتواه والذي

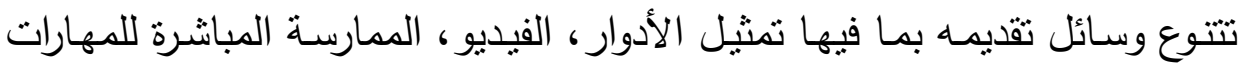

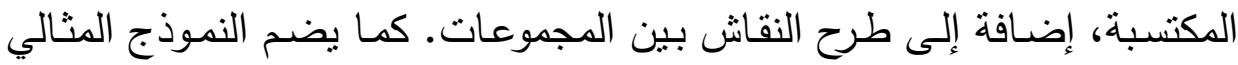
استخدام لغة بسيطة، مثقفة وتجنب: المبالغة في القراءة والكتابة وتكرار المواضيع لين

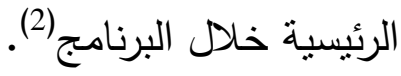

\section{ثنانيا: التخطيط للزواج ويناء الأسرة}

يقول كوفمان في كتابه علم اجتماع الثتائي "كان الزواج مؤسسـة يدخلها

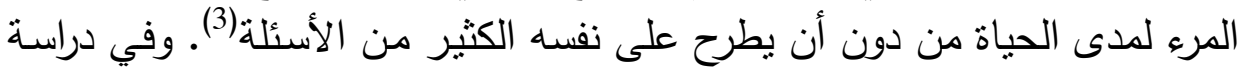

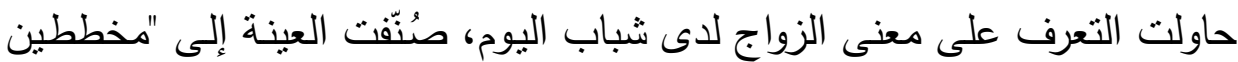

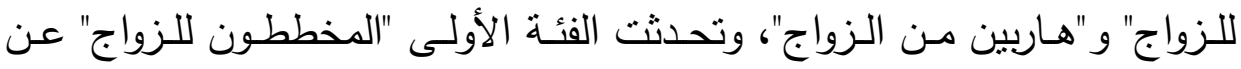

Virginia Knox and David Fein, Designing a Marriage Education Demonstration and Evaluation for Low-Income Married Couples, (may, 2005) pp. 1-29,

http://www.mdrc.org/publications/shm_guideline.pdf

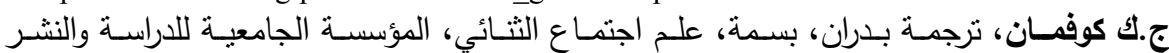


الاستعداد للزواج بأنه يعني استقرار المشـاعر ، النضـج وتحقيق أهداف شخصية، وهية

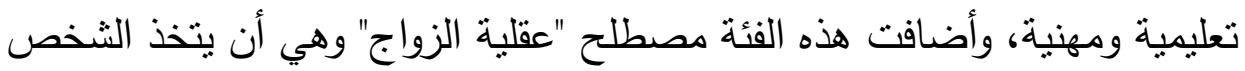

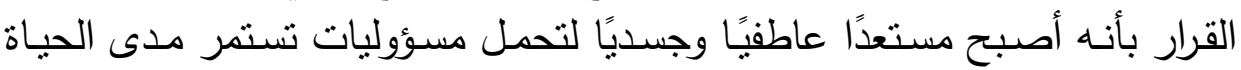

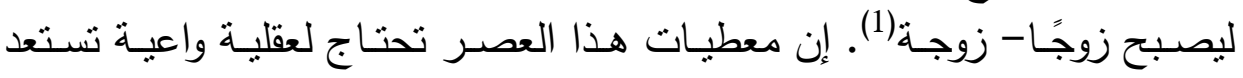
للمستقبل ولتحدياته، وهنا تقول مـاري لامانـا في كتابها اتخاذ الخيارات في عالم عالم متغير : "الزواج هو علاقة مختلفة، علاقة تشمل عنصرين مهمين: الالتزام الذي

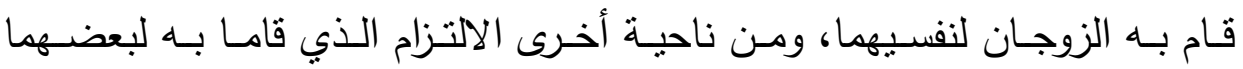
البعض. الزواج يُعلن عن قرار يستمر لمدى الحياة، والعلاقة بين الزوجين خلفين خلاحله

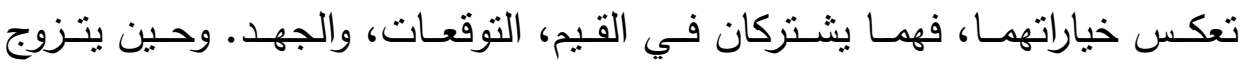

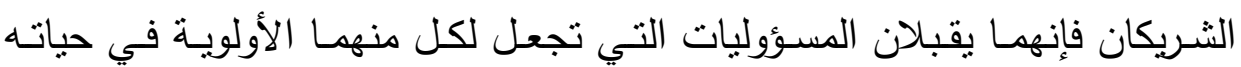
ويعملان بجهد لضمان استمرار العلاقة بينهما. وحفل الزفاف هي مناسبة اجتماعية

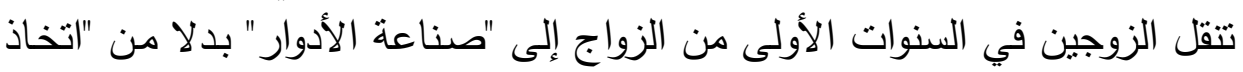

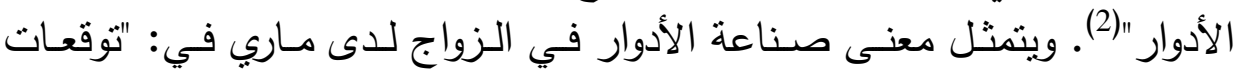

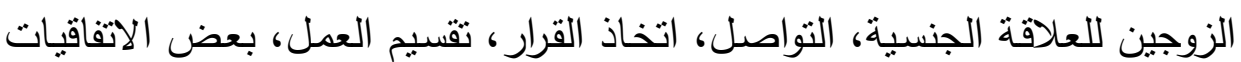

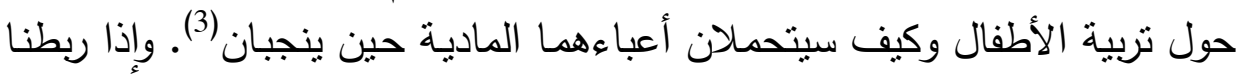

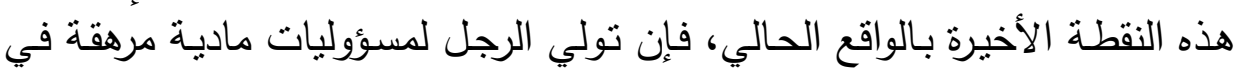

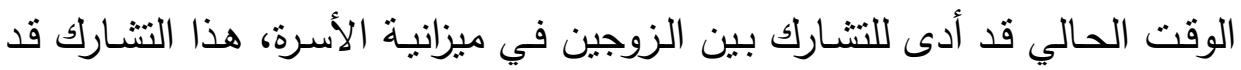

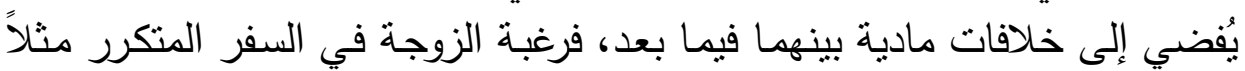

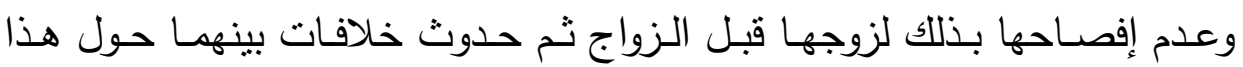

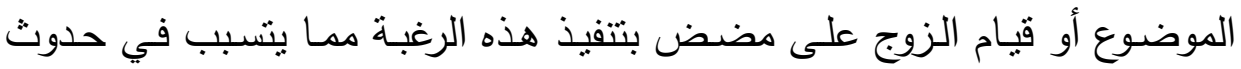
مشكلة ماديـة في ميزانيـة هذا البيت الحديث التأسيس والذي بيؤدي بعد ذلك إلى إلى

Maria Kefalas, Marriage is more than being together: The meaning of Marriage among young adults in the United States, Network on Translation to Adulthood Research Network working Paper, (sept, 2005), p p. 8-15, www.transad.pop.upenn.edu/downloads/ kefalasmarriagenorms.pdf

Mary Lamanna, Marrige and Families: making choices in a Diverse Society, Sixth

Edition, New Jersey: Wadsworth Publishing Company, (2006), pp: 220-224. 
مشكلات مختلفة منها تراكم الديون وتبادل اللوم بين الزوجين، أو حتى إذا تركنا

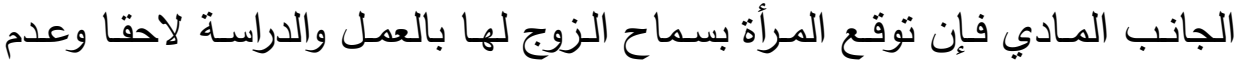

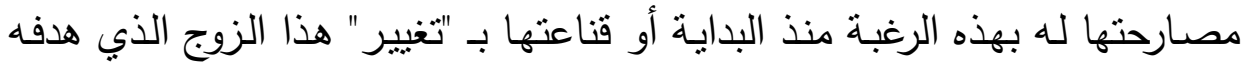

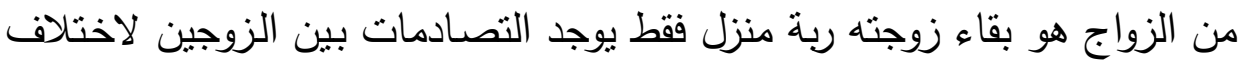

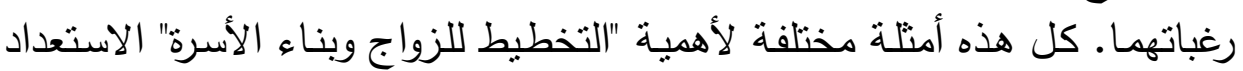

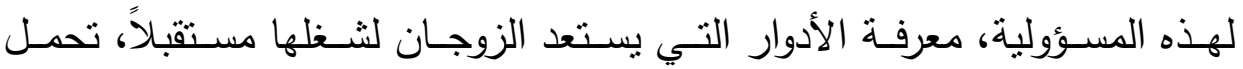

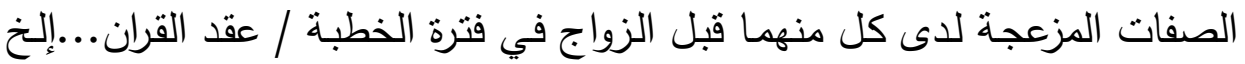

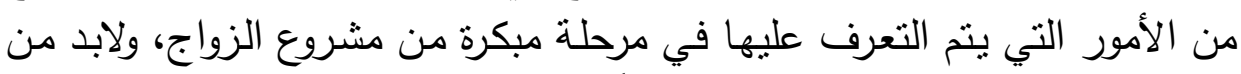
أخذها في الاعتبار والتكيف معها مستقبلاً.

ثالثا: الادراسات السابقة

على المستوى المحلي أظهرت نتـائج دراسـة أظهرت دراسـة آل درعـان

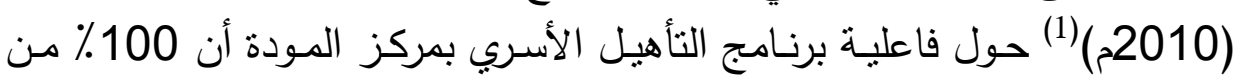

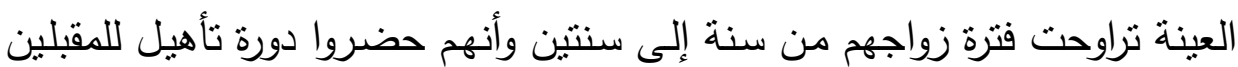

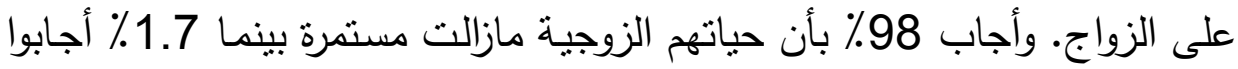

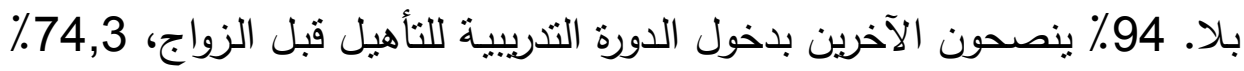

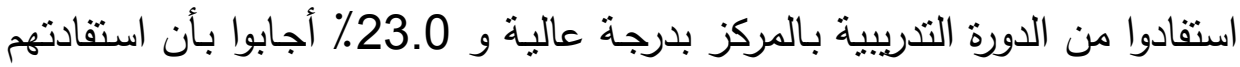

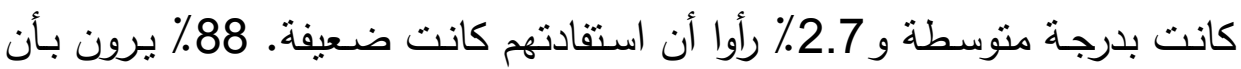

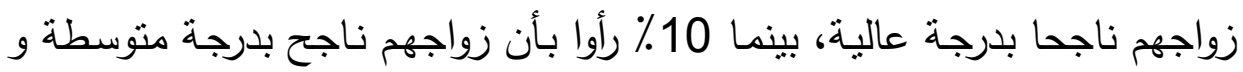

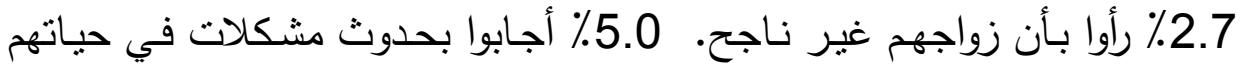

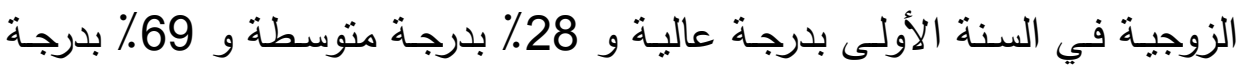
ضعيفة. دلت نتائج دراسة منصور بن عسكر (2009م) (2) حول اتجاهات الأسرة

(1) علي آل درعان، فاعلية برنامج الثأهيل الأسري بمركز المودة: دراسة استطلاعية، مركز المودة الاجتماعي

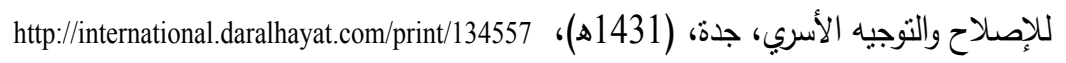

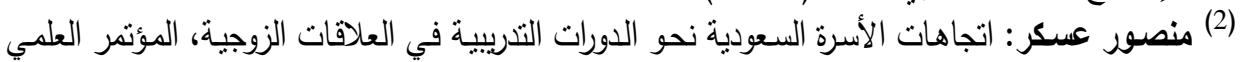

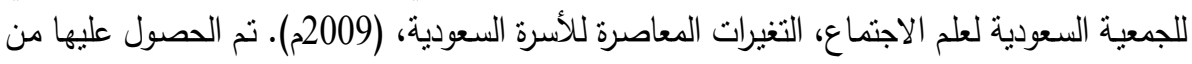

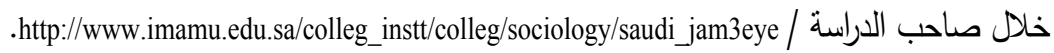


السعودية نحو الدورات التدريبيـة في العلاقـات الزوجيـة إلى أن بعض العنـاوين

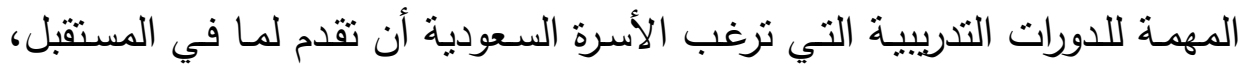

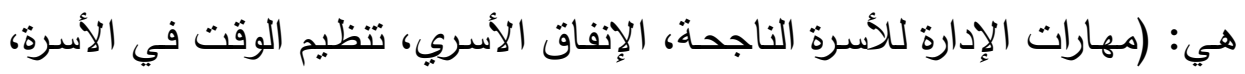

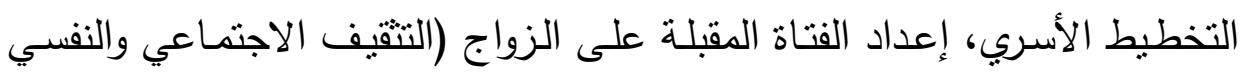

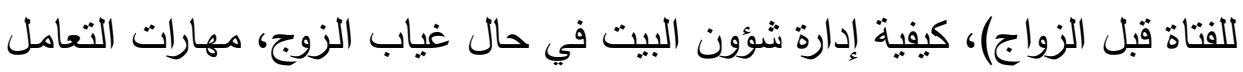

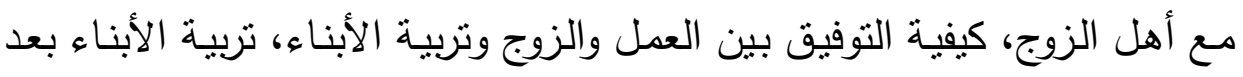

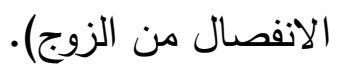

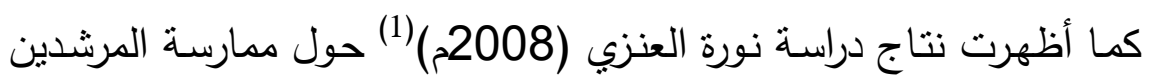

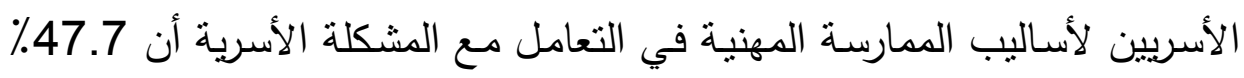

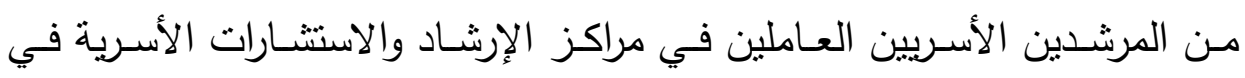

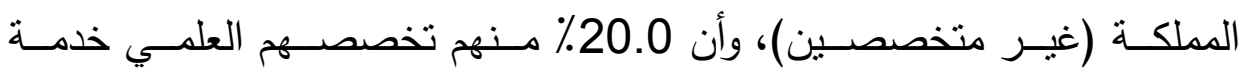

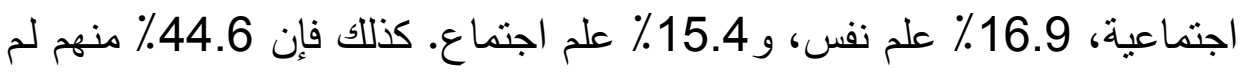

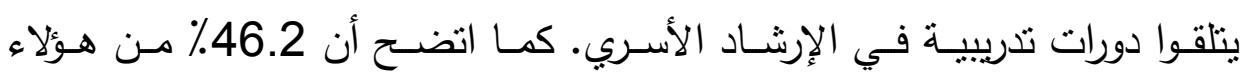

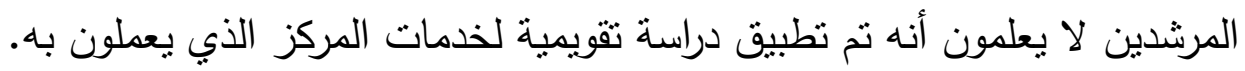

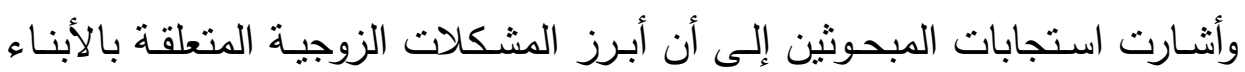

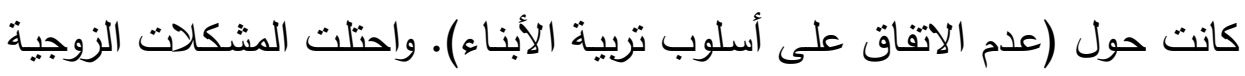

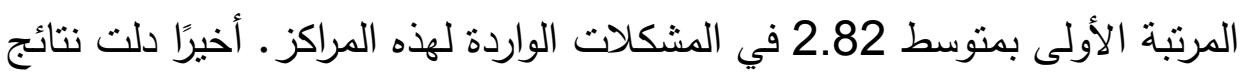

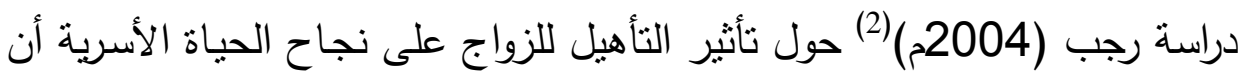

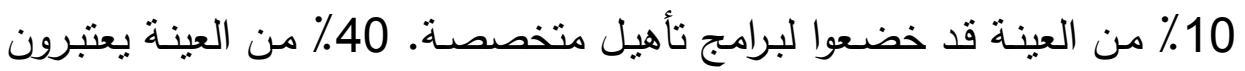

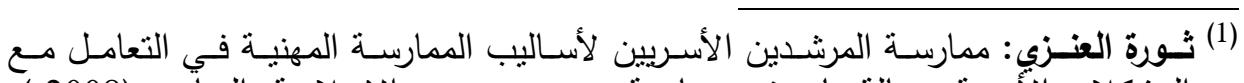

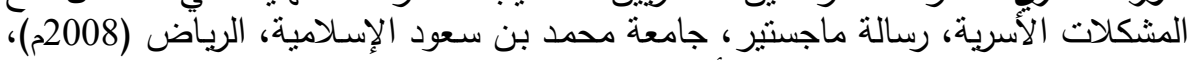

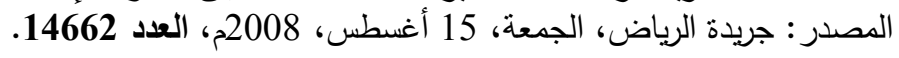
كريم رجب وآخرون، تأثير التأهيل للزواج على نجاح الحياة الأسرية، مركز البحوث البهاث

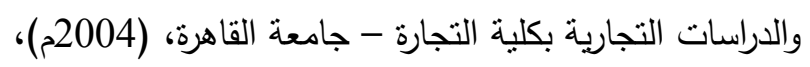
http://www.pathways.cu.edu.eg/news/uf/24186_10-B9_Projects.doc 


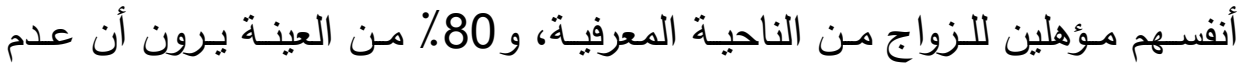

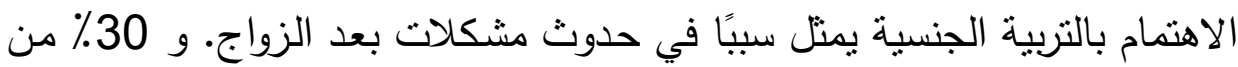

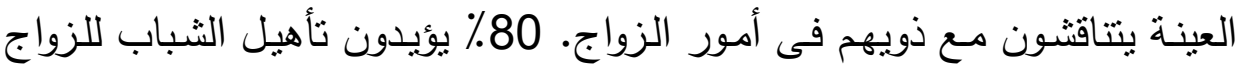

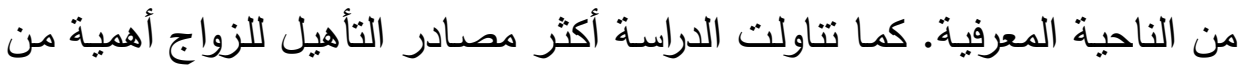

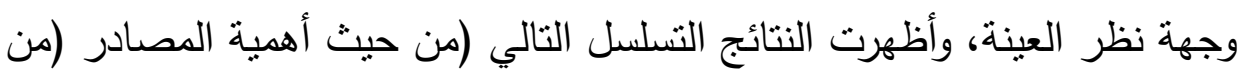

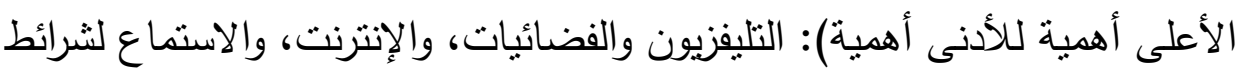
الكاسيت، وحضور الدورات التدريبية، وسماع الخطب في المساجد، وقراءة الكتب.

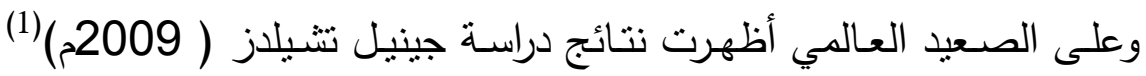

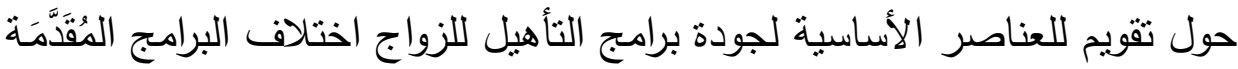

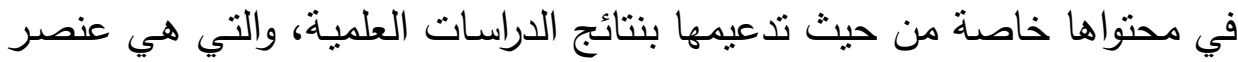

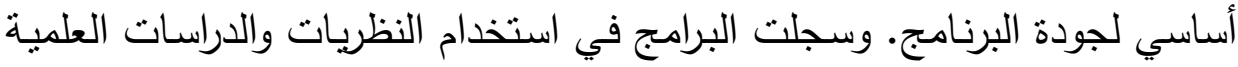

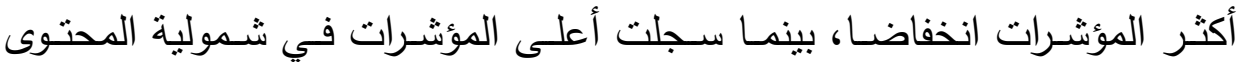

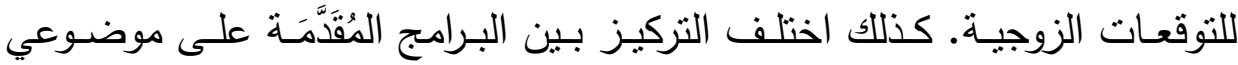

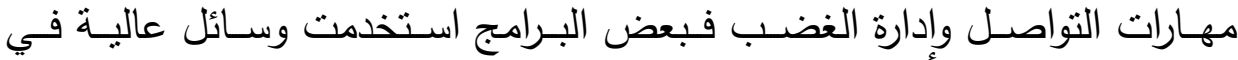
التدريب كالأشكال التوضيحية والبعض الآخر لم يستخدم وسائل في تطبيق هذه المهارات. وأظهرت البرامج التي تم تصميم محتواها لثريحة معينة من المستقفيدين

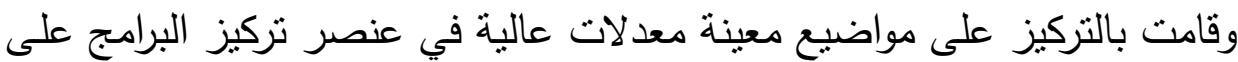

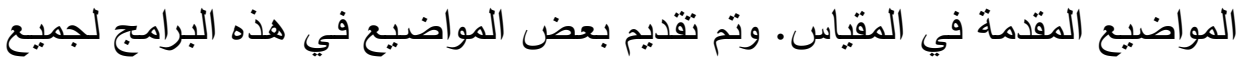

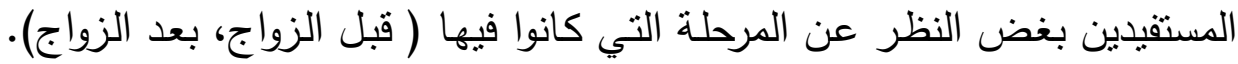

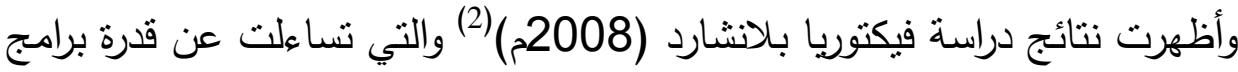

Geniel childs, Marriage preparation education programs: an evaluation of essential elements of quality, M. Sc. Thesis, submitted to the faculty of Brigham Young University Master of Science School of Family Life, Brigham Young University, (August, 2009), pp: 4-69, Contentdm.lib.byu.edu/ETD/image/etd2983.pdf

Victoria Blanchard, Does Marriage and Relationship Education Improve Couples Communication? A Meta-Analytic Study, A thesis submitted to the factuality of Brigham Young University in Partial fulfillment of the requirements for the degree of Master of 
التقافـة والعلاقـة الزوجيـة على تحسـين التواصـل بـين الـزوجين فعاليـة التأهيـل للزواج/التقافة الزوجية على الذكور والإناث على حد سواء وتأثير برامج التأهيل

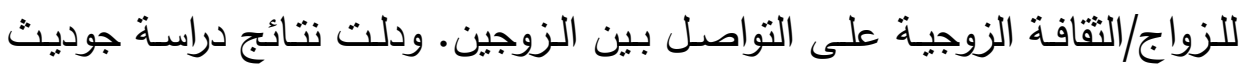

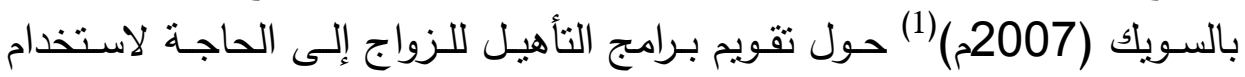
وسـائل مختلفة في تقديم البرامج لمناسبة أنواع مختلفة من المواقف في العلاقة الزوجية. وأن برامج التأهيل للزواج تكون فعالة بشكل كبير حين يُعطى المستقيدون

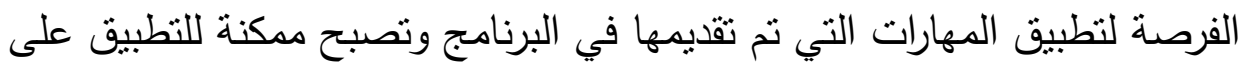

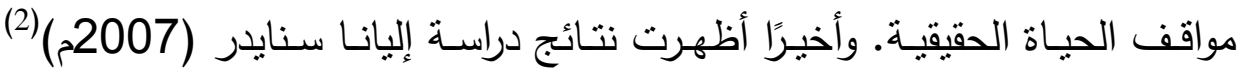

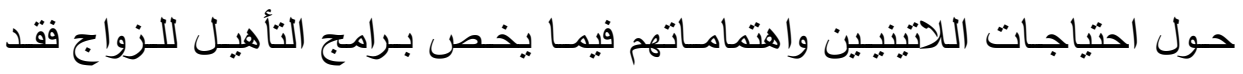
أظهرت نتائجها بأن أغلب المستفيدات من هذه البرامج - لإناث - كنّاث مهتمات

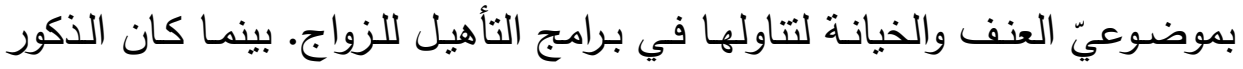
أكثر اهتمامًا بالمواضيع: الأمسان المادي تطوير مهارات التواصل وزيـادة مهارات

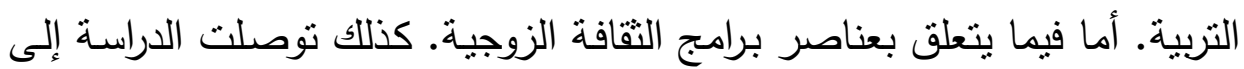

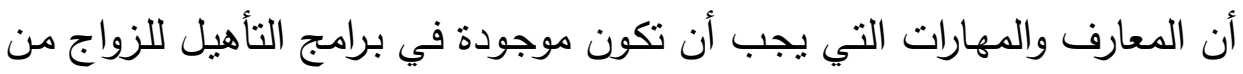

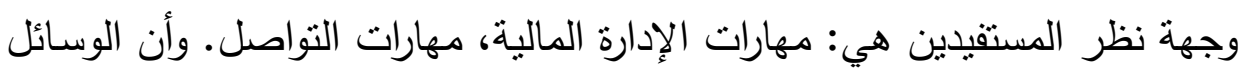

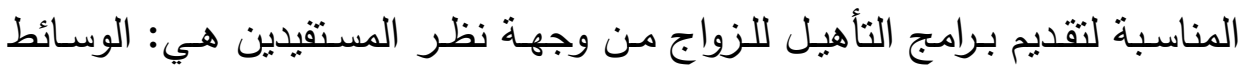
المتعددة، المواد المكتوبة، التدخلات العلاجية، التمارين العملية. من ناحية أخرى فان حجم الوقت المناسب لتتفيذ برامج التأهيل للزواج من وجهة نظر المستقيدين

Since Department of Marriage Family and Human Development, Brigham Young University (April, 2008), PP: 4-58, contentdm.lib.byu.edu/ETD/image/etd2278.pdf

Judith Balswick and Jack Balswic, Marriage Enrichment Program Evaluation, Family

Ministry: Empowering Through Faith, '(2007) pp:1-14, http://www.finef.org/pages/printable_page. cfin?page_ID =86.

Iliana Snyder, Assessing perceived marriage education needs and interests of latino individuals in Utah county, M. Sc.Thesis, submitted to the faculty of, Brigham Young University, in partial fulfillment of the requirements for the degree of Master of Science Marriage and Family Therapy Program, Brigham Young University UTAH (April, 2007),pp: 5-6, contentdm.lib.byu.edu/ETD/image/etdl674.pdf 
هو : ساعة إلى ثلاث ساعات في الأسبوع. والمبلغ الذي يمكن دفعه لحضور برامج

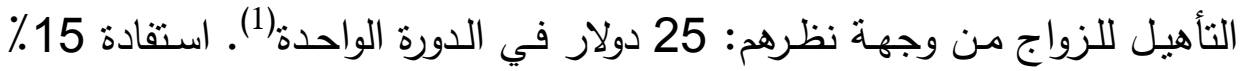

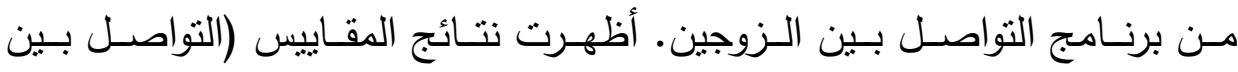

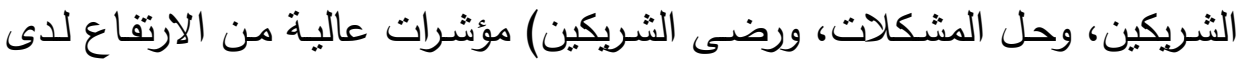

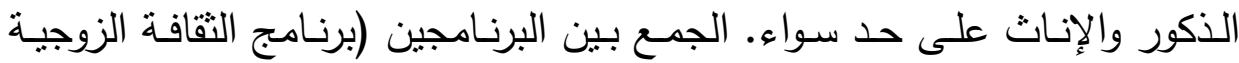

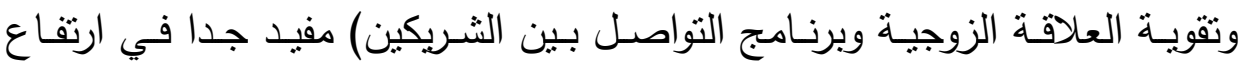

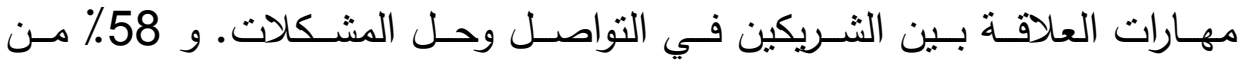
المستقيدين أثناروا بفائدة الدمج بين البرنامجين التهين.

رابعًا: المدخل النظري

\section{علم اجتماع الثنائي(2)}

هي محاولة نظرية لإيجاد فرع جديد من فروع علم الاجتماع يهتم بيناء

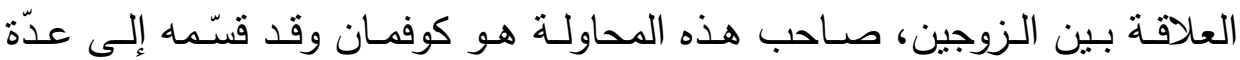

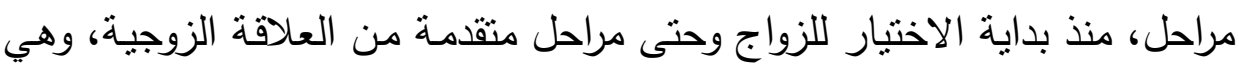

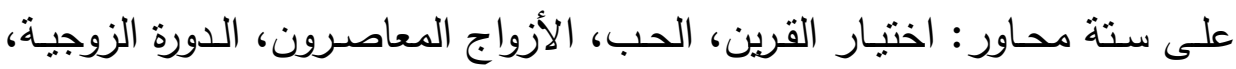
العمل المنزلي، والحياة الثنائية. وتطرح هذه المحاولة النقاط التالية: أ- شغف المراحل الأولى يغطي أسباب الخيار مما يشكّل عودة تدريجية إلى رؤية

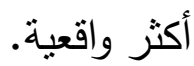

ب- القيام بالأعمال المنزلية يتطلب قرارات مشتركة لم يكن الزوجان مهيئين لها. ج- الزوجان ينتقلان من لعب دور ولدين يمكنان عند ذويهها إلى دور زوجين يسكنان منزلهما الخاص.

د- ينبغي اتخاذ قرارات عديدة تتعلق بتحديد عمل كل من الزوجين في فترة قصير 


\section{نسبيا.}

هـ - الثبان الذين يكونون ثنائيا تدفعهم خفّة البداية(1) إلى عدم إعطاء هذه المشاكل

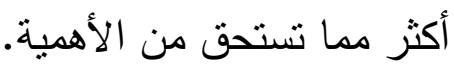

يرسم هذا المنظور مخططًا للمراحل التي يمر بها الزواج وتكوين الحياة الزوجية في المراحل الأولى، ويركز على أهمية الوعي والتخطيط والذي يترجمهيا

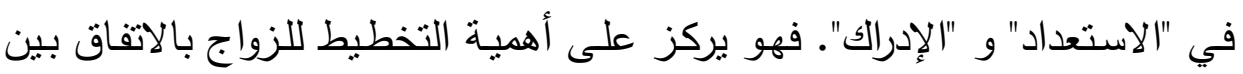

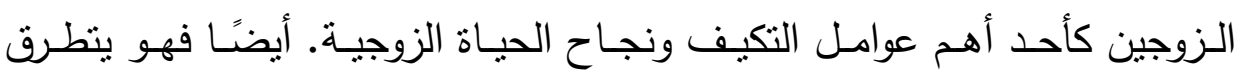
للنوقعات العالية "الخيالية" لدى الثريكين قبل الزواج والتي نؤثثر سلبًا على مستقبل

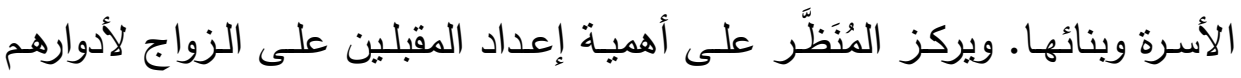

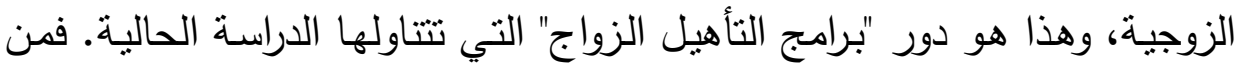

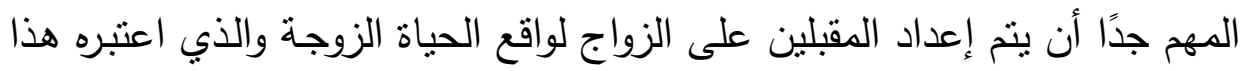

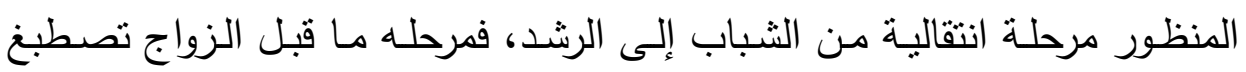

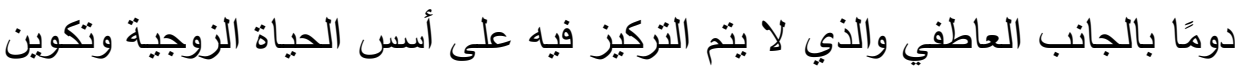

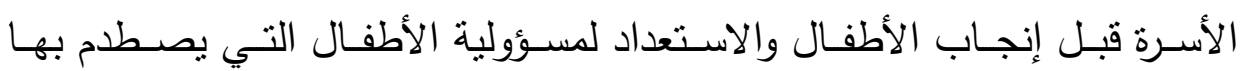

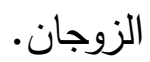

\section{منهج الدراسة وعينتها وأداؤها}

منهج الدراسة

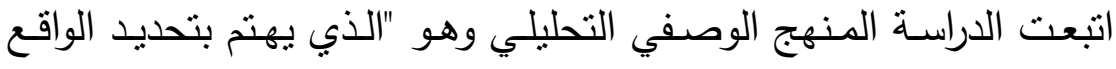

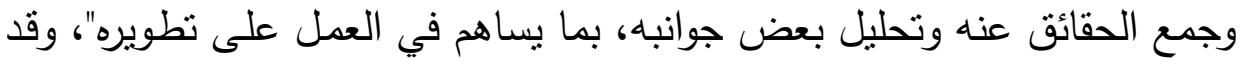

(1) تعبير استخدمه كوفمان لوصف مرحلة ما قبل الزواج، وهو برمز إلى ضعف إدراك المقبلين على الزواج في هذه المرحلة لحجم المسؤولية التي سيقبلون عليها. 
تم استخدام أسلوب الوصف الكمي.

\section{المجال المكاني للاراسة}

تمثل مجتمع الدراسة في بعض برامج التأهيل للزواج التي تقدمها بعض لتصان المراكز في مدينة جدة المستفيدين من هذه البرامج. بعض.

\section{المجال البشرى للاراسة}

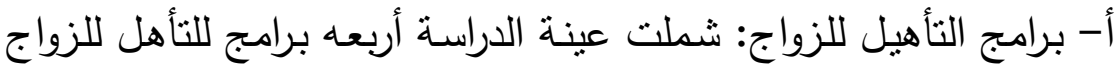

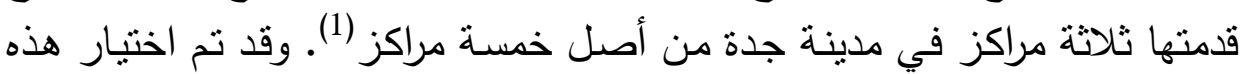

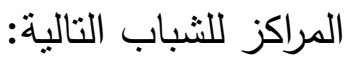

1. تقدم هذه المراكز الثناث برامج التأهيل للزواج، بطريقة منتظمة شهريًا،

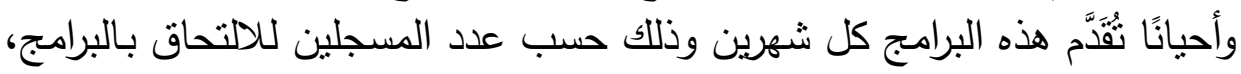

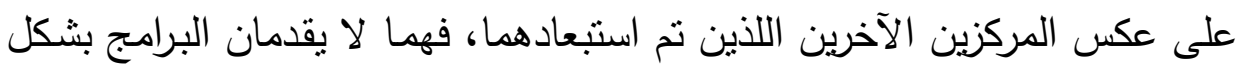

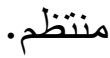

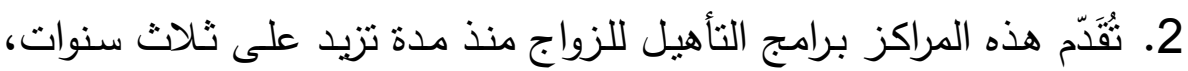

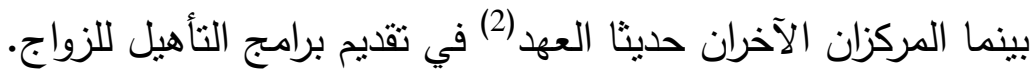

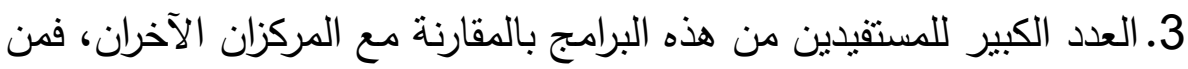

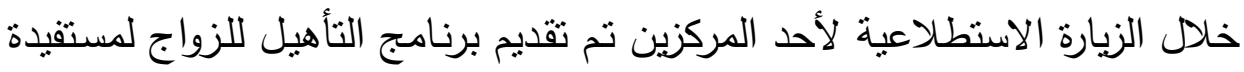
واحدة فقط.

ب- المستفيدون من برامج التأهيل للزواج: شملت عينة الدراسة 72 مفردة، 32 من الإناث و 40 من الذكور.

(1) وتم الحصول على الأوراق الرسمية الني تعرف بالدراسة الحالية وتقديمها للمراكز لتطبيق

$$
\text { من ستة أثشهر إلى سنة. }
$$




\section{1- استبانة وصف برامج التأهيل للزواج وإثتملت على:}

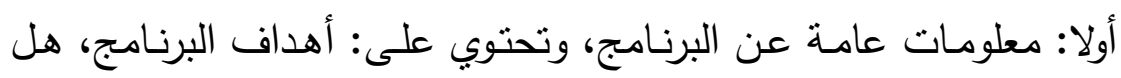

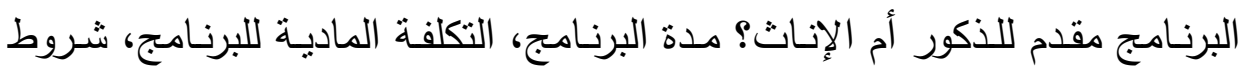

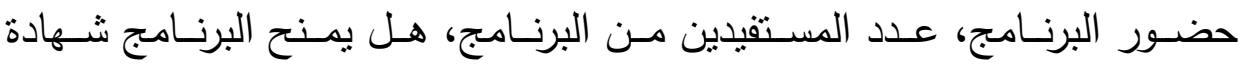

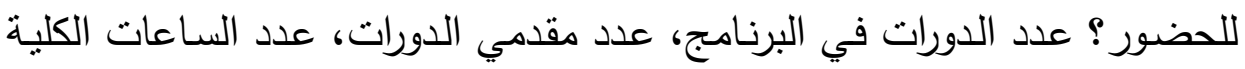
للبرنامج، عدد الساعات لكل دورة، عدد الدورات في اليوم الواحد، وأخيرًا ماذا تُقََّّم البرنامج للمستفيدين.

ثانيا: محتوى البرنامج، ويحتوي على: عناوين الدورات في البرنامج، عدد

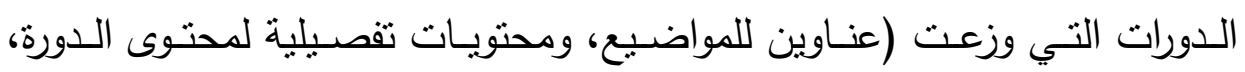
وتمارين، وأوصت بقراءة كتب متخصصـة، واستبانه تقويمية)، وعدد الدورات التي ولي

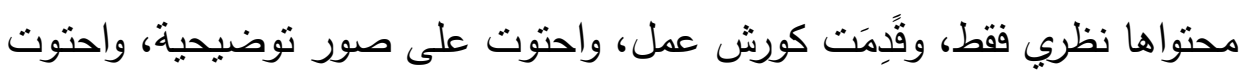

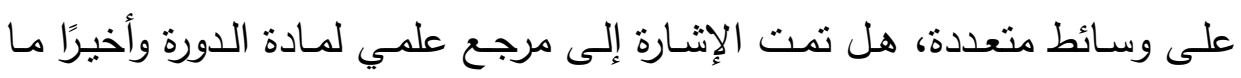

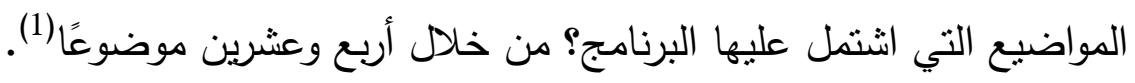
2- استبانة مقابلة للمستفيدين من برامج التأهيل للزواج:

وتتاولت رأي المستفيدين حول عدد من المتغيرات مثل: مدة، ومواضيع،

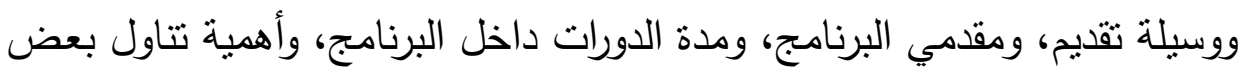
المواضيع في برامج التأهيل للزواج، (المدة / الرسوم / المكان) المناسبين لبرامج

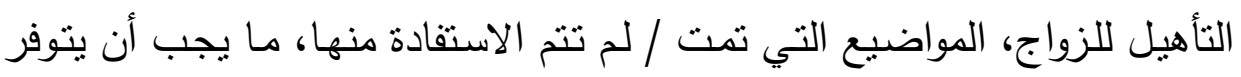
في مقدمي برامج التأهيل للزواج، وبعض الخصائص الديموغرافية لهم. صدق وثبات أداة الدراسة 
الصـدق الظـاهري: تم تحكيم أداة الدراسـة بعرضـها على المختصـين في

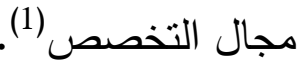

صدق المحتوى: وفيه تم الرجوع للندوات المستخدمة في الدراسات السابقة

من استبانات ومعايير، والاستفادة منها في صباغة أداتي الدراسـة: استمارة وصف لتف البرنامج واستمارة المقابلة.

الثبـات: نظـرًا لأن اختبـار ثبـات أداة الدراسـة يسـتلزم طريقـة إعـادة الاختبـار أو استخدام صورة بديلة عند إعادة الاختبار، فلم يتم إجراء اختبار للثبات قبل إجراء

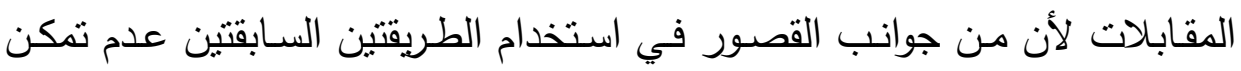
الباحث من تطبيق الأداة إلا لمرة واحدة فقط، وذلك لارتفاع تكلفة الاختبار في فترة

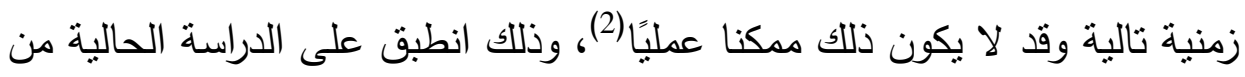
خلال:

- - صعوبة إجراء المقابلات مع المستفيدين والمستقيدات، خاصة في ظل عدم استجابة البعض منهم، لأن مدة كل مقابلة لا تقل عن 10 دقائق أو 15 دقيقة لكل مبحوث.

- - طول الفترة الزمنية بين برامج التأهيل للزواج، فأحيانًا تصل المدة لشهرين

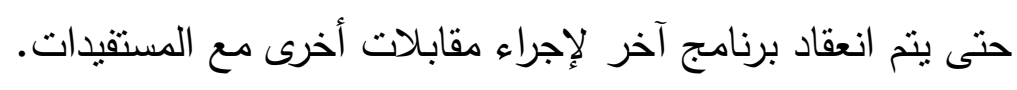

- - ضيق الوقت الذي تم فيـه إجراء المقابلات، لأن الوقت المناسب لإجراء

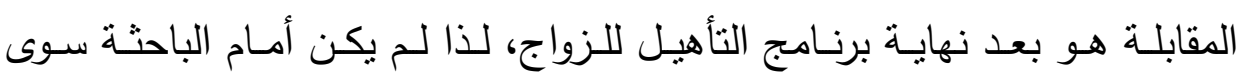

(1) المحكّمون هم: إسماعيل قشقري: الأستاذ المساعد بقسم علم الاجتماع والخدمة الاجتماعية،

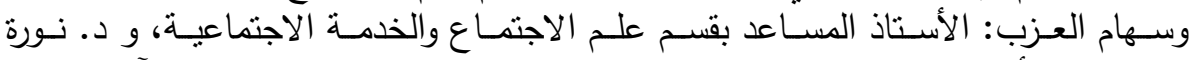

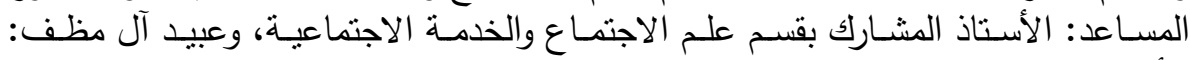

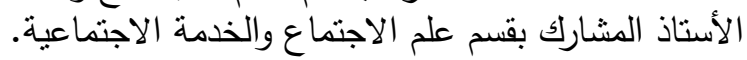
محمد نوري: تصميم البحوث العلمية في العلوم الاجتماعية والسلوكية، جدة، مكتبة خدمة الأمة

$$
\text { الطالب، (2000م)، ص ص: 345-347. }
$$


طريقتين: إجراء المقابلات في آخر البرنامج لعدد معين من المستقيدات، والحصول على أرقام المستفيدات الأخريات اللواتي لديهن استعداد لإجراء المقابلة(1). وبنـاءً عليه تم اختيار معامل "ألفا كرونبـاخ" لاختبـار ثبـات المقياس وقد

بلغت درجة الثبات 0.63. المجال الزمني للاراسة بـدأت عمليـة جــع البيانـات مـن تــاريخ(2) 29 صـفر 1431هـ إلـى 25جمادى الآخرة 1431هـ. وتم حضور 112 ساعة تدربيية موزعة كالتالي: - المركز الأول: البرنامج المقدم للإناث: 3 أيام في كل يوم 4ساعات (بواقع

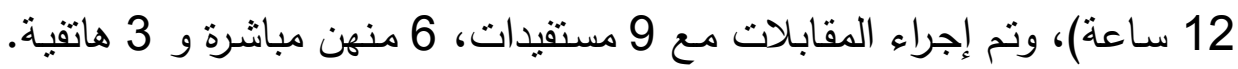

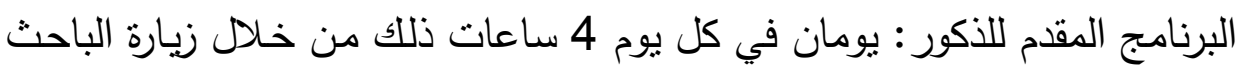
المساعد كما سبق التوضيح ونم إجراء 40 مقابلة هاتقية مع المستقيدين. - المركز الثاني: 10 أيام في كل يوم 4 ساعات (بواقع 40 ساعة) وتم إجراء 15 مقابلة مباشرة مع المستقيدات. - المركز الثالث: 20 يومًا في كل يوم 3 ساعات (بواقع 60 ساعة ) وتم إجراء 8 مقابلات هاتقية مع المستفيدات. منهجية تحليل البيانات تحليل وصفي لبرامج التأهيل للزواج، وتضمن: - - أهداف البرامج محل الدراسة. - - الفــة المسـتهدفة، والمـدة، والتكلفـة الماديـة، وشـروط الحضــور ، وعـدد

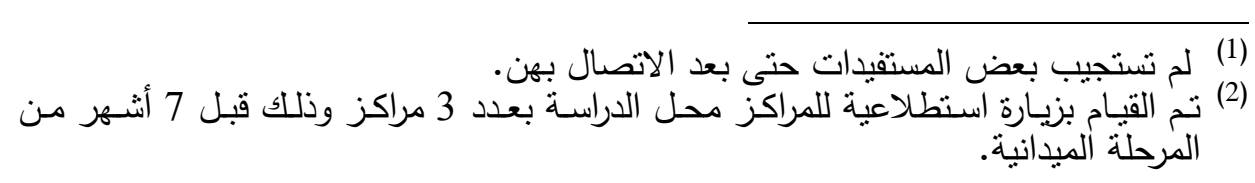


المستقبدين، ومنح شهادة حضور • - - عدد الدورات، وعدد مقدمي الدورات، وعدد الساعات الكلية للبرنامج، ومدة كل دورة، وعناوين الدورات في البرامج محل الدراسة. - - ما تم توزيعه في البرامج محل الدراسة، وسائل تقديم البرامج محل الدراسة، وعدد الدورات التي تتاولت كل موضوع من المواضيع الأربعة والعشرين المحددة لئرة

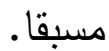

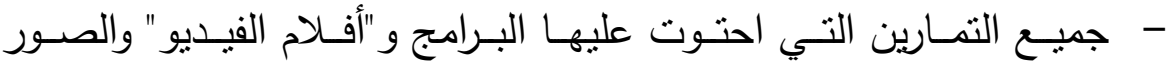
التوضيحية التي تم عرضها، بذكر : تطبيق التمرين، عدد التمارين، الهدف من كل تمرين، وعدد "أفلام الفيديو" والصور التي تم عرضها، ومحتواهما. - متوسـط نتـاول محتوى البـرامج لهذه المواضـيع، وتـم تقربـغ البيانـات في برنامج (SPSS) وتصنيف تتاول كل برنامج لكل موضوع حسب: طرح الموضوع

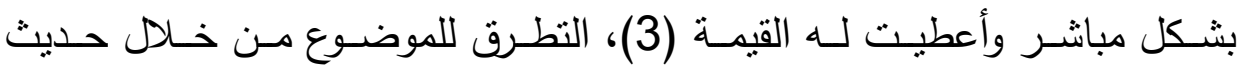
المحاضر وأعطيت له القيمة (2) ولم يتم طرح الموضوع وأعطيت له القيمة (1). - - المعلومات المشتركة بين البرامج دن خلال تتاول هذه المواضيع.

\section{الإحصاء الوصفي}

حيث تم استخدام برنامج (SPSS) للحصول على نتائج الدراسـة من خلال عرض النتائج بـالتكرارات والنسـب المئويـة، إضـافة إلى حسـاب المنوسط وإجـراء اختبار كا2 لجودة التوفيق للتعرف على مدى وجود ارتباط ذي دلالة إحصائية بين المتغيرات محل الدراسة.

\section{نتائج الدراسة}

ا. المواضيع التي تناولتها يرامح التأهيل للزواج - تناولت جميع برامج التأهيل للزواج الموجهة للذكور والإناث معًا، ضمن 
المحـاور الرئيسـة للبرنـامج المواضيع التاليـة: الهدف مـن الزواج، والتقافـة الجنسية، والحوار بين الزوجين.

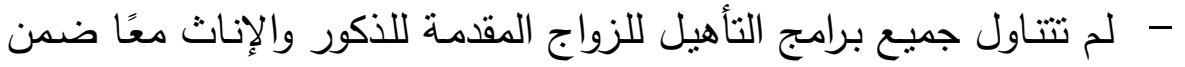

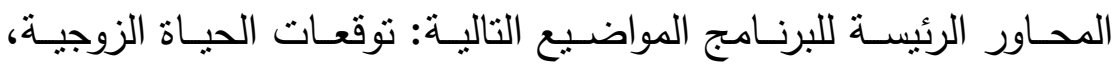

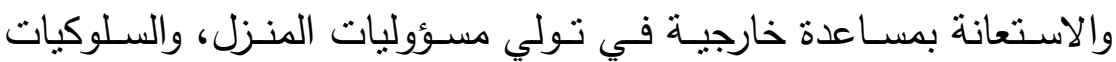

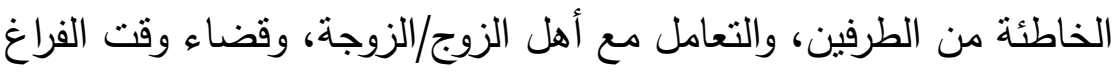

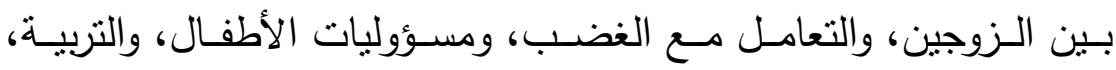

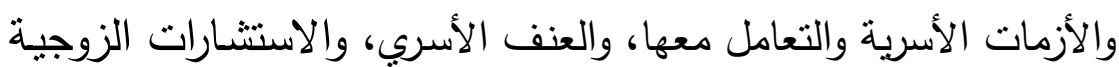

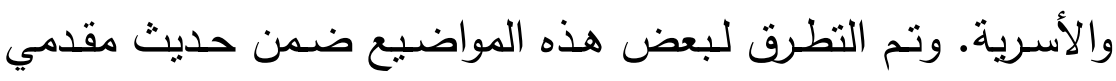

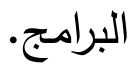

2. الوسائل المستخدمة في تثقيد يرامح التأهيل للزواج كان مجموع الدورات في البرامج محل الدراسـة 41 دورة، تم تقديمها

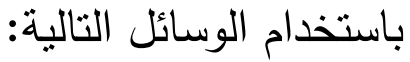

- قُقِّمَت 22 دورة عن طريق وسيلة العرض التقديمي بمحتوى نظري. - وزعت 16 دورة تمارين على المستقيدين/المستقيدات بمجموع20 تمربنا لم يتم تطبيق 6 منها، وتم تطبيق 14 دنها داخل الدورات. - قُدَِّت 14 دورة بشكل تطبيقي/مهاري في مركزين من أصل 3 مراكز ، في الطهي والمكياج وترتيب وتتظيم المنزل. - - استخدمت 10 دورات صورًا توضيحية لمحتواها، استخدمتها جميع البرامج فيما يتعلق بالجانب الطبي. - - احتوت 4 دورات على وسائط متعددة (فيديو) كالتالي: فيديو يوضح الحياة الزوجيـة السـيدة/فيديو آخر يوضـح الحيـاة الزوجيـة غير السعيدة، فيديو يوضـح

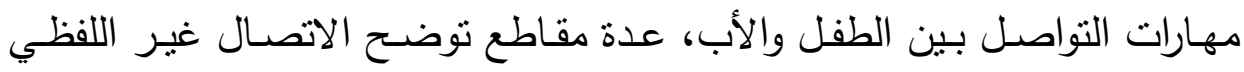


3. مدة الوقت الذي تقدم فيها هذه البرامج

لم تتفق أب من البرامج على مدة زمنية معينة، فقد استغرقت كل منها مدة مختلفة هي:

المركز الأول: يومان (للاكور)، ثناثة أيام (للإناث).

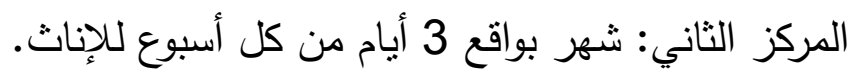
المركز الثالث: خمسة أسابيع يوميًا للإناث. 4. أوجه التشابه والاختلاف بين البرامج المُقَََّمَة

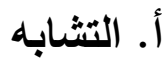

- - تتاولت جميع البرامج المواضيع التاليـة: الهدف من الزواج، التقافة

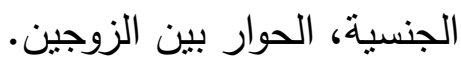
- قدمت جميع البرامج دورة واحدة فقط في اليوم الواحد. - لئمان. - منحت جميع البرامج شهادة حضور للمستقيدين منها. - - بلغ منوسط عدد الساعات لكل دوره في كل البرامج 4 ساعات في اليوم

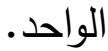

- ل لم تتشر جمع البرامج إلى المرجع العلمي لمحتوى الدورات/البرنامج.

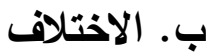

- اختلفت البرامج في تحديد/ذكر أهدافها فقد ذكرها برنامجان ولم يذكرها

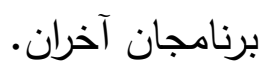

- - اختلفت البرامج في: المدة الزمنيـة لتنفيذها، عدد السـاعات في كل برنامج، عدد الدورات في كل برنامج. - - اختلفت البرامج في رسوم الالتحاق بها كالتالي: 


$$
\text { البرنامج الأول المقدم للذكور والإناث: } 150 \text { ريالاً سعوديًا. } 1500 \text { ربال سعودي. } 3300 \text { ربال سعودي. }
$$

- - اختلفت البرامج في شروط حضور البرنامج، فقد اشترط برنامج واحد للإناث من أصل اثتان أن تكون المستفيدات متزوجات ولم تشترط البرامج الثناثة الأخرى سوى دفع الرسوم.

- - اختلف عدد المستفيدين من هذه البرامج.

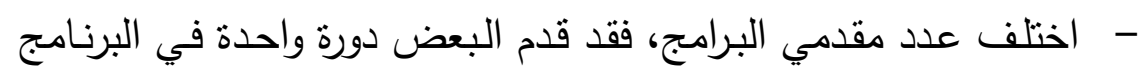
وقدم البعض الآخر أكثر من دورة، وصلت في إحدى البرامج إلى خمس دورات حول موضوعين مختلفين. - مزعت بعض البرامج استمارات لتقويم الدورات أو البرنامج ككل، وتميز برنامج واحد فقط بتوزيع استمارة تقويميه في نهاية كل دورة. ولم تتفق البرامج على البرن محاور معينة للتقويم.

- مزعت بعض الدورات قائمة بمحتوباتها ولم يوزعها بعضها الآخر •

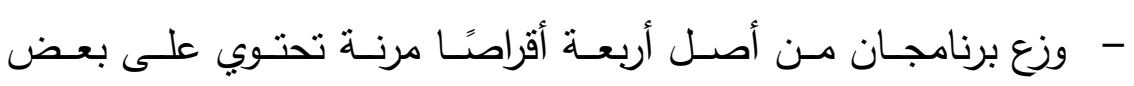
العروض التقديمية لدورات البرنامج. 5 ـ الخصائص الايموغرافية للمستفيدين من البرامج الحالة الاجتماعية

مثنل المتزوجـون 64\% مـن المستقيدين، أمـا مـن لازالـوا في مرحلـة عقد

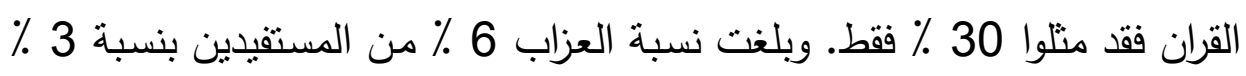
لدى الذكور والإناث على حد سواء. وفي الفرق بين الذكور والإناث في الحالة

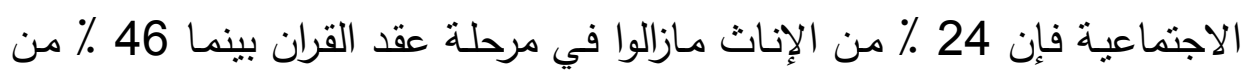


الذكور هم من المتزوجين. وذللك يجعلنا نتساءل: هل محتوى برامج التأهيل للزواج

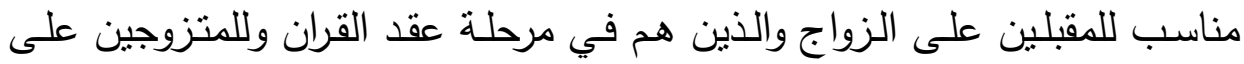
اختلاف مدة زواجهم على حد سواء؟

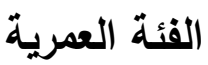

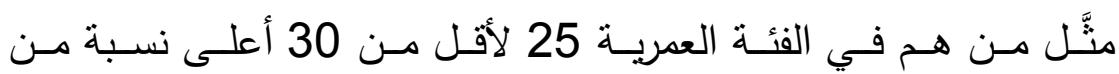

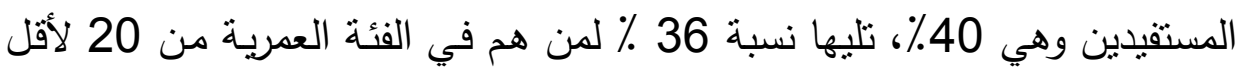

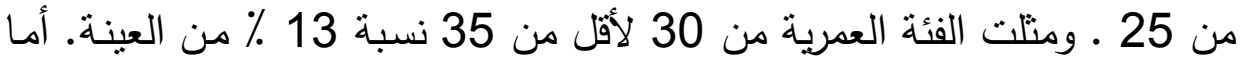

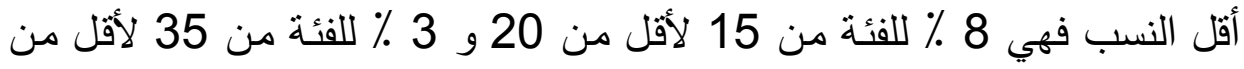

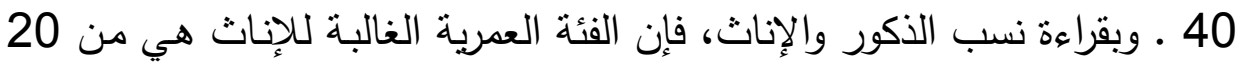

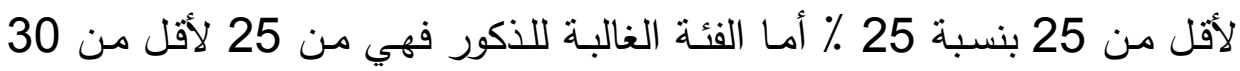

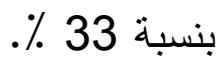

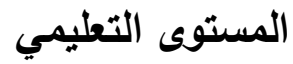
نسبتان عاليتان ومتقاربتان للمستفيدين هما 43 ٪ و 40٪، كانت بانت الأولى

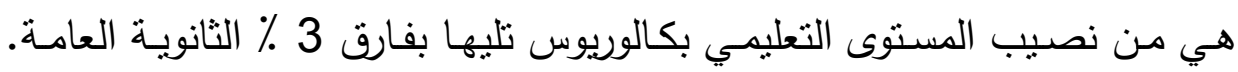

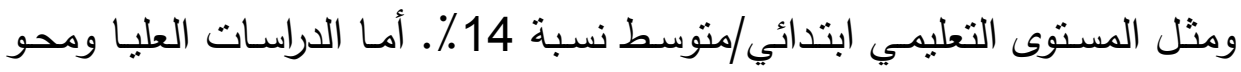

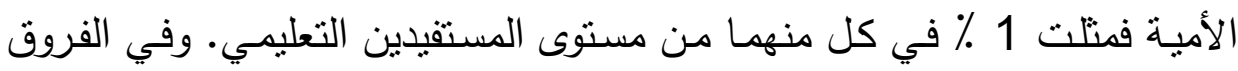

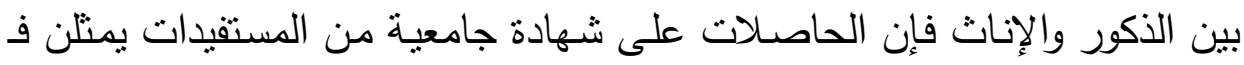

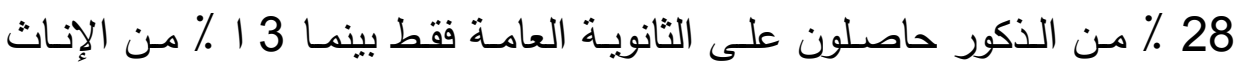
حاصلات على الثانوية العامة. المستوى الاقتصادي أ- حيازة المسكن

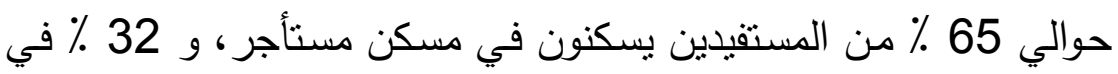

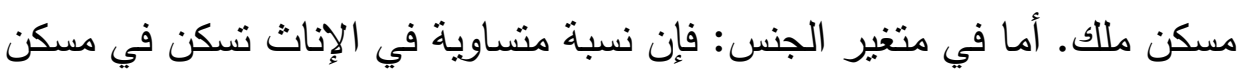

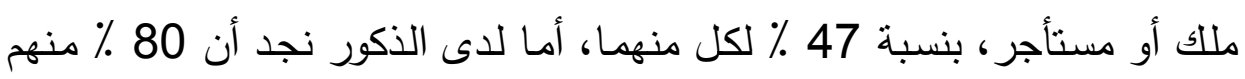




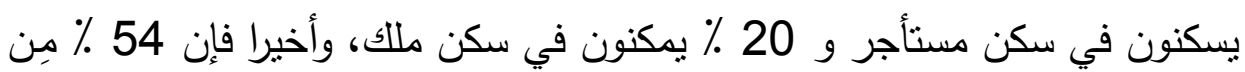

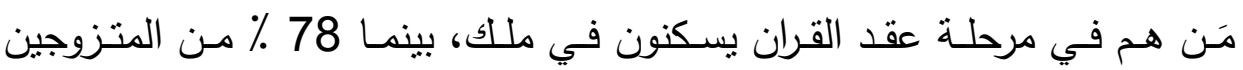

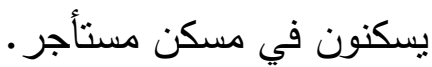
ب- الحالة المهنية

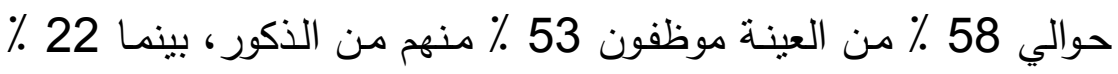

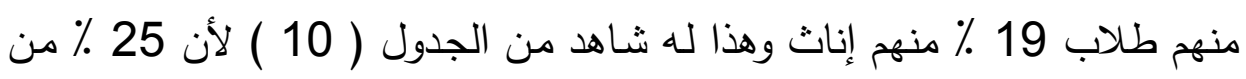

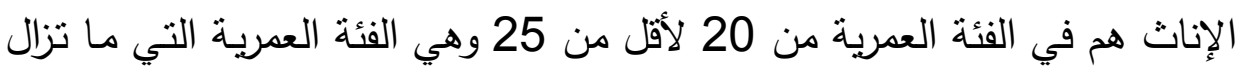
في صفوف الدراسة، و 19 \% غير موظفين جميعهم من الإناث. 6. وجهة نظر المستفيدين حول برامج التأهيل للزواج

نال رضى المستفيدين عن وسائل تقديم البرنامج ومقدمي البرامج المرتبة

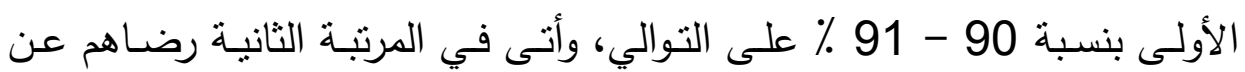

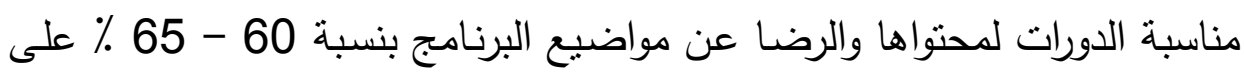

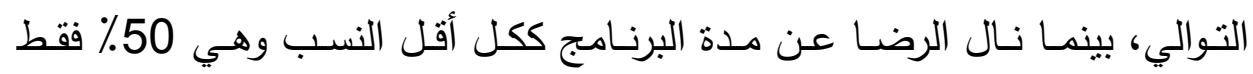
(جدول) (ل)

جدول (1) وجهة نظر المستفيدين حول برنامج التأهيل للزواج

\begin{tabular}{|c|c|c|c|c|c|}
\hline الإحصائية & العلاقة بين المتنيرات & p & $\%$ & \multicolumn{2}{|l|}{ المتغير } \\
\hline$* * *$ & مدة البرنامج من الإنىاث عن & 2.25 & 50 & مدة البرنامج كافية لشمول & \\
\hline **** & 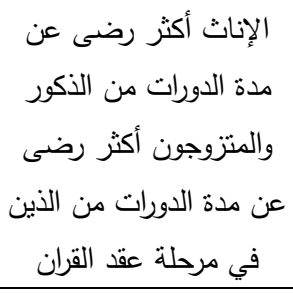 & 2.43 & 60 & مناسبة الدورات لمحتواها & الدرامج| \\
\hline$* * *$ & شُلكور أكثر رضى عنى البرني & 2.54 & 65 & تناولتها برامج التنأهيل التزاجي & البرامج \\
\hline
\end{tabular}




\begin{tabular}{|c|c|c|c|c|c|}
\hline & من الإناث & & & $\begin{array}{c}\text { لما يحتاجه المقبلون على الزواج } \\
\text { لمبل }\end{array}$ & \\
\hline * & لا توجد علاقة بين الجنس & 2.89 & 90 & 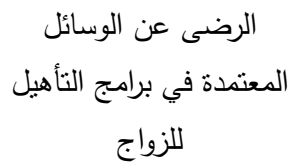 & تقديم \\
\hline * & $\begin{array}{c}\text { المستيم الدورات ورضيدين عن مقدمي } \\
\text { البرامي }\end{array}$ & 2.92 & 91 & مقدمي البرامج لديهم القدرة & مقدمي \\
\hline
\end{tabular}

(****) اختلاف معنوي عند مستوى معنوية (0.00)، (*) اختلاف معنوي عند مستوى معنوية (0.10)

من الناحية الأخرى فقد أظهرت نتائج اختبار كا(2) لجودة التوفيق وجود علاقة ذات دلالـة إحصـائية مـا بين كل مـن الرضـا عن مـدة البـرامج ومواضـيع البرامج وما بين متغير الجنس، فالذكور أكثر رضا عنهما من الإناث، كذلك فإن هنـالك علاقة مـا بين الرضـا عن مدة الدورات ومـا بين متغيـري الجنس والحالة الاجتماعية فالإناث والمتزوجون أكثر رضا عن مدة الدورات مقارنة بالذكور والذين في مرحلة عقد القران. أخيرًا فإن نتائج اختبار كا2 أظهرث عدم وجود علاقة ذات دلالة إحصائية مـا بين الرضـا عن وسائل تقديم البرنامج ومقدمي البرامج وما بين متغير الجنس.

\section{7. أكثز المواضنع التي تم الاستفادة منها من خلال حضور البرنامج}

اسـتفادت الإنـاث من: الحوار والتواصـل بين الزوجين الحقوق والواجبات

التقافـة الجنسـبة الفـروق بـين المـرأة والرجل أنــاط الثخصسيات والجانـب الطبـي والطهي وتقدير الـذات والتـزين والـديكور والإتيكيـت، بينمـا اسـتفاد الـكور مـن: التعامل مع الزوجة، الأمور الدينية، العلاقة الزوجية.

8. المواضيع التي كان المستقيدون يتوقعون أن يشملها البرنامج من وجهة نظر المستفيدات: تفاصيل الحياة الجنسية بشكل طبي، الحمل والولادة، وتربية الأطفال/العناية بالطفل/التعامل مع مرض الطفل الطف، والعنف الأسري 
الموجه من الآباء نحو الأبناء، وصحة المرأة ومحافظتها على لياقتها الجسدية بعد

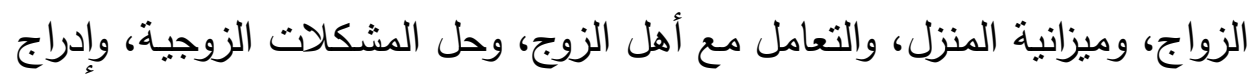

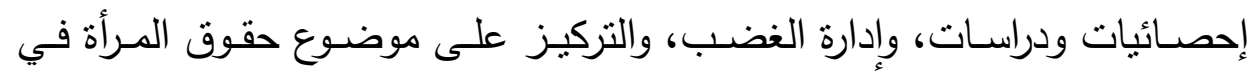

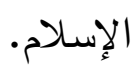

من وجهة نظر المستفيدين: التوسع في الجانب الجنسي، فترة ما قبل/

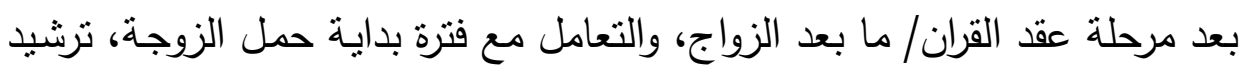
ميزانية الأسرة، وكيفية حل المشكلات.

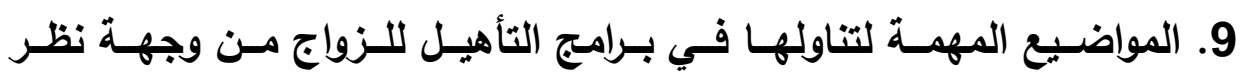
المستفيدين

ما بين 90 - 97 ٪ من المستقيدين رأوا أهمية تتاول المواضيع (حقوق

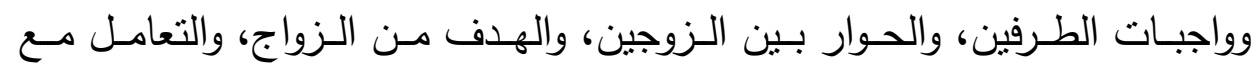

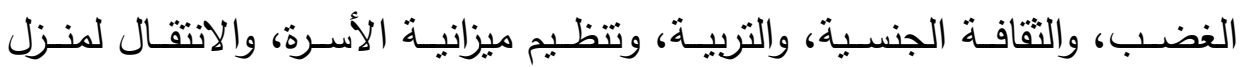

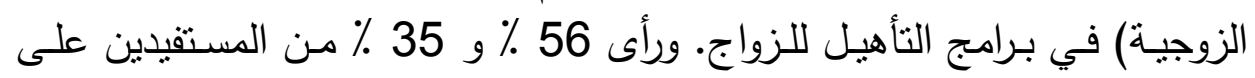

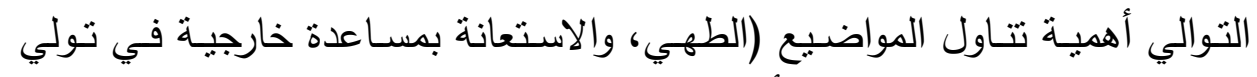

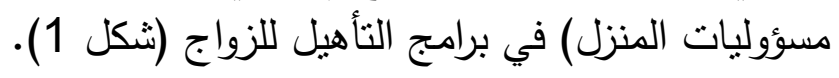




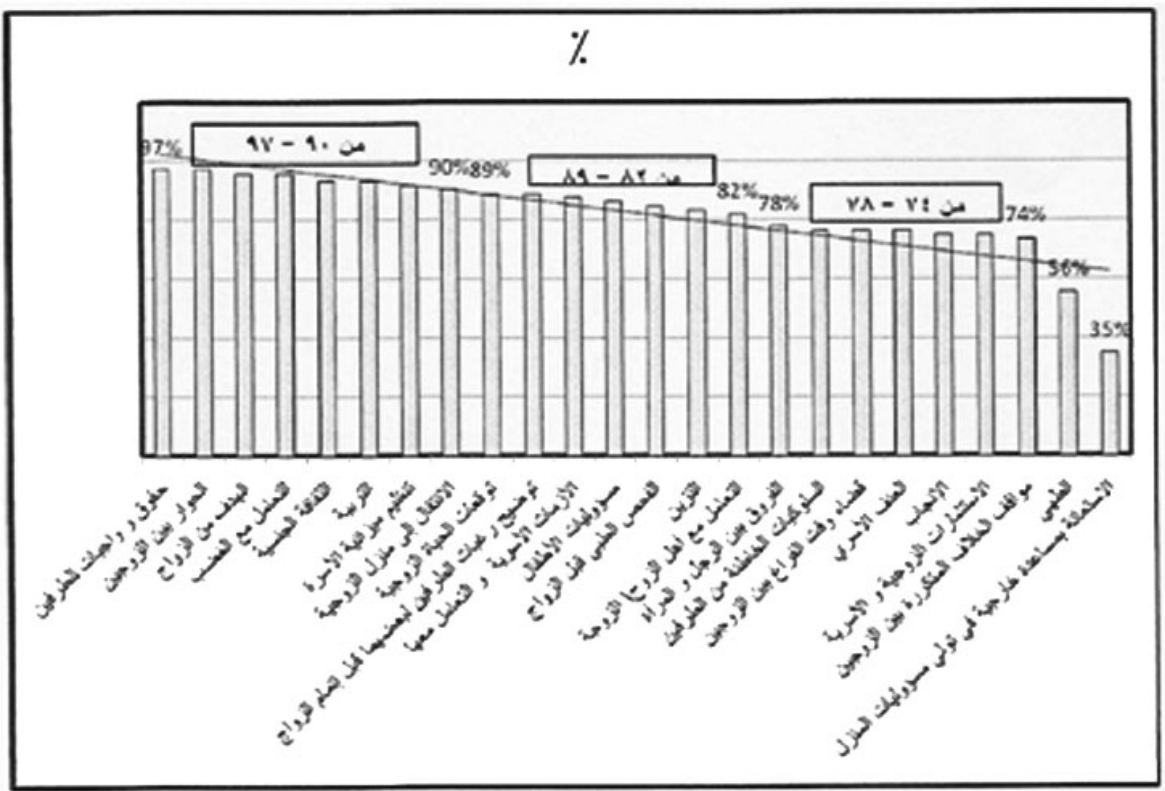

شكل (1) المواضيع التي نالت آهميتها نسبًا مئوية عالية من وجهة نظر الأكور والإناث كذلك فإن هناك فروقًا في المتوسطات بين الذكور والإناث في أهمية تناول برامج التأهيل للزواج لبعض المواضيع فقد أعطى الذكور أهمية أعلى من الإناث لتتاول المواضيع: الاستعانة بمساعدة خارجية في تولي مسؤوليات المنزل، والطهي

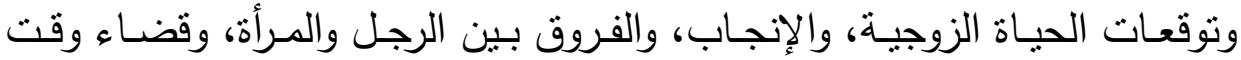

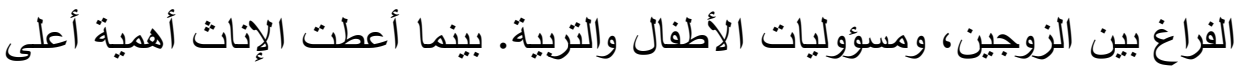
من الذكور لتتاول موضوع : الفحص الطبي قبل الزواج فقط (جدول 2). جدول (2) أهمية تناول بعض المواضيع في برامج التأهيل للزواج من وجهة نظر المستفيدين بالمتوسطات

\begin{tabular}{|c|c|c|c|c|}
\hline \multirow{2}{*}{ الانحراف } & \multicolumn{3}{|c|}{ المتوسط } & \multirow{2}{*}{ الموضوع } \\
\hline & الأكور & الإناث & الكل(1) & \\
\hline 0.16549 & 2.97 & 2.96 & 2.97 & الحوار بين الزوجين \\
\hline
\end{tabular}

(1) تم ترتيب المتوسطات تتازليًا من الأعلى للأدنى. 


\begin{tabular}{|c|c|c|c|c|}
\hline 0.16549 & 3.00 & 2.93 & 2.97 & حقوق وواجبات للطرفين \\
\hline 0.20123 & 2.97 & 2.93 & 2.95 & الهدف من الزواج \\
\hline 0.23067 & 2.97 & 2.90 & 2.94 & الثقافة الجنسية \\
\hline 0.28527 & 2.95 & 2.93 & 2.94 & التعامل مع الغضب \\
\hline 0.32501 & 2.95 & 2.87 & 2.91 & تتظيم ميزانية الأسرة \\
\hline 0.32501 & 3.00 & 2.81 & 2.91 & التربية \\
\hline 0.35823 & 2.85 & 2.93 & 2.88 & توضيح رغبات الطرفين لبعضهما قبل إتمام الزواج \\
\hline 0.37294 & 2.95 & 2.78 & 2.87 & توقعات الحياة الزوجية \\
\hline 0.37294 & 2.90 & 2.84 & 2.87 & الانتقال إلى منزل الزوجية \\
\hline 0.34826 & 2.97 & 2.71 & 2.86 & مسؤوليات الأطفال \\
\hline 0.38659 & 2.92 & 2.78 & 2.86 & الأزمات الأسرية والتعامل معها \\
\hline 0.38735 & 2.82 & 2.81 & 2.81 & التعامل مع أهل الزوج/ الزوجة \\
\hline 0.42215 & 2.85 & 2.78 & 2.81 & 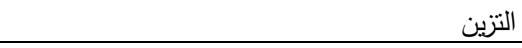 \\
\hline 0.50176 & 2.70 & 2.90 & 2.79 & الفحص الطبي قبل الزواج \\
\hline 0.45943 & 2.87 & 2.62 & 2.76 & الفروق بين الرجل والمرأة \\
\hline 0.47451 & 2.87 & 2.56 & 2.73 & قضاء وقت الفراغ بين الزوجين \\
\hline 0.50969 & 2.85 & 2.56 & 2.72 & الإنجاب \\
\hline 0.58676 & 2.75 & 2.68 & 2.72 & العنف الأسري \\
\hline 0.56761 & 2.70 & 2.71 & 2.70 & السلوكيات الخاطئة من الطرفين \\
\hline 0.57259 & 2.67 & 2.71 & 2.69 & الاستشارات الزوجية والأسرية \\
\hline 0.63156 & 2.70 & 2.59 & 2.65 & مواقف الخلاف المتكررة بين الزوجين \\
\hline 0.58073 & 2.62 & 2.40 & 2.52 & الطهي \\
\hline 0.82175 & 2.17 & 1.84 & 2.02 & المنزل الاسـتعانة بمســاعدة خارجيـة فـي تـولى مسـؤوليات \\
\hline
\end{tabular}

\section{نتـائج الدلالـة الإحصـائية بـين أهميـة تنـاول هذه المواضـيع مـن وجهـة نظر المستفيدين ويين بعض الخصائص الايموغرافية}

أظهرت نتائج اختبار كا2 لجوده التوفيق وجود علاقة ذات دلالة إحصائية

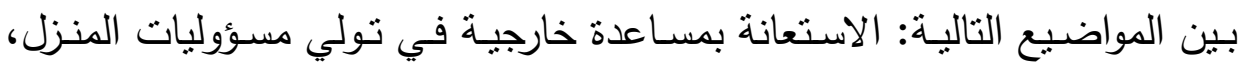

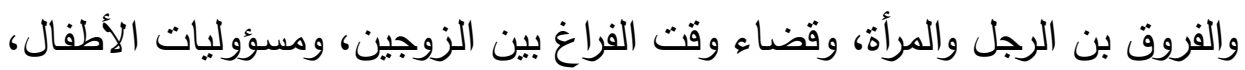

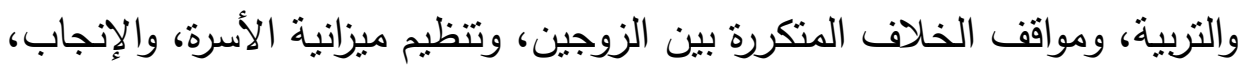

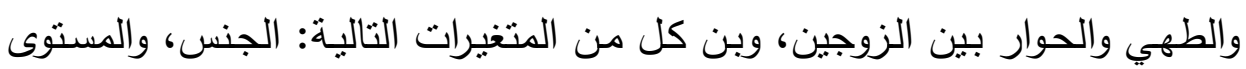

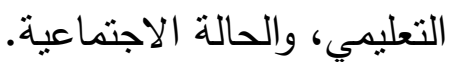


واتضح بأن الذكور أكثر اهتمامًا من الإناث بتتاول المواضيع: (الاستعانة

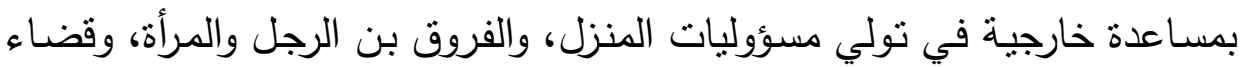

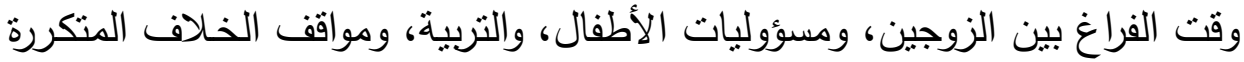
بين الزوجين، وتتظيم ميزانية الأسرة).

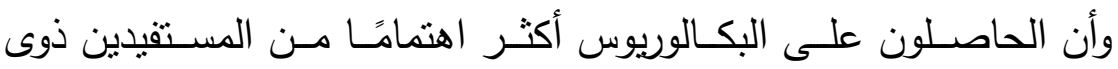

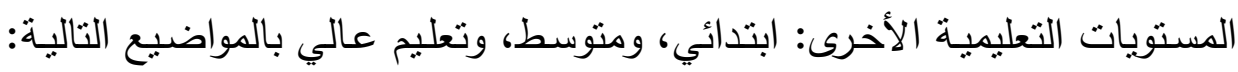

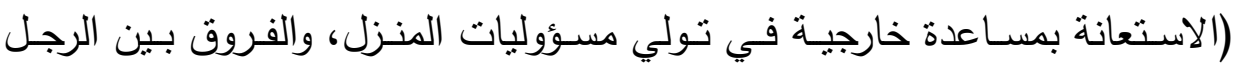

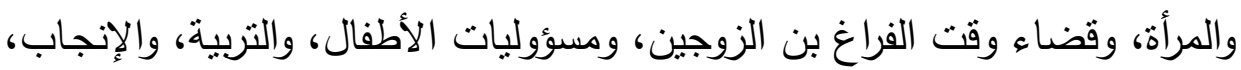
والطهي).

وأخيرًا فإن العزاب والمتزوجون أكثر اهتمامًا مِن مَن مازالوا في مرحلة عقد

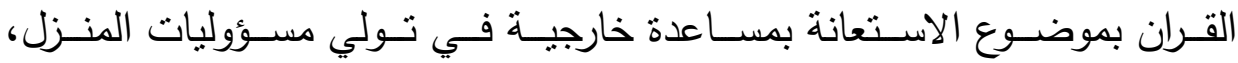

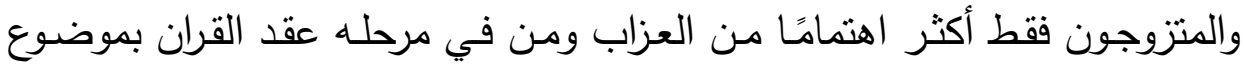

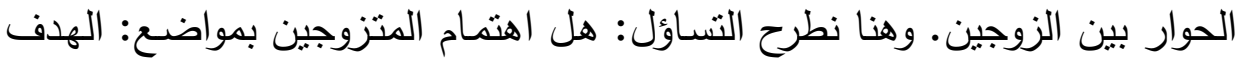

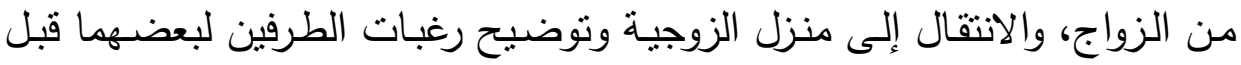

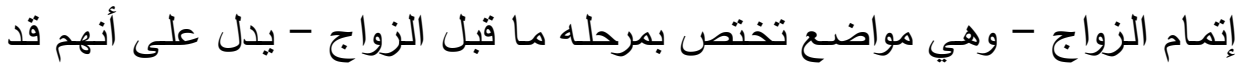

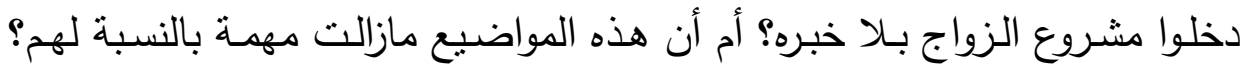

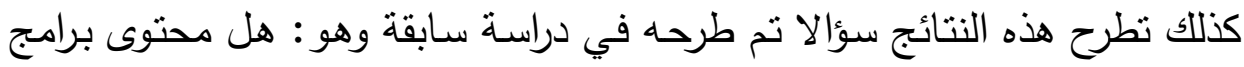

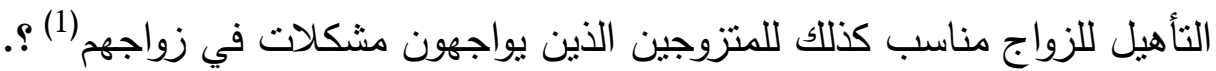

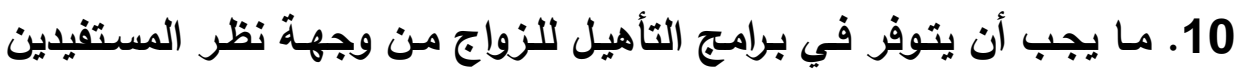

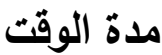

بلغ منوسط مدة الوقت المناسبة من وجهة نظر الإناث (شهر)، وبلغ لاى

Elizabeth Fawcett, Is marriage education effective? a meta-analytic review of marriage ${ }^{(1)}$ education programs, D. Thesis dissertation, submitted to the faculty of Brigham Young University in partial fulfillment of the requirements for the degree of Doctor of Philosophy Department of Marriage Family and Human Development, Brigham Young University, (August, 2006), pp: 4-54, contentdm.lib.byu.edu/ETD/image/etdl681.pdf 
الذكور (خمسـة أيسام ). وهناك علاقة ذات دلالـة إحصـائية بين الجنس وبين مدة الوقت المناسبة لتتفيذ برامج التأهيل للزواج من وجهة نظر المستقيدين، فالذكور أكثر اختيارا للمدة الأقصر والإناث أكثر اختيارا للمدة الأطول.

\section{المبلغ المناسب لدفعه كرسوم للبرنامج}

بلغ منتوسط المبلغ المناسب لدفعه كرسوم لحضور برامج التأهيل للزواج من وجهة

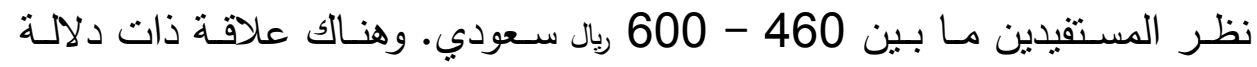
إحصائية بين الجس والمبلغ المناسب لدفعه كرسوم لحضور برامج التأهيل للزواج

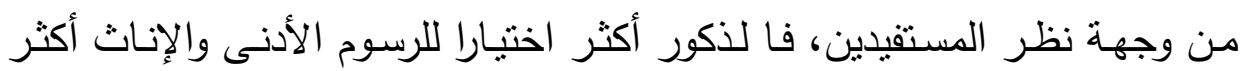
اختيارا للرسوم الأعلى.

وسيلة تقديم الاورات

حصلت وسيلة العروض التقديمية على أعلى النسب المئوية 37 ٪ يليها (ورش عمل، وفيديو وأصوات، وتمارين تطبيقية لمواضيع البرنامج) بنسب مئويـة اعبة

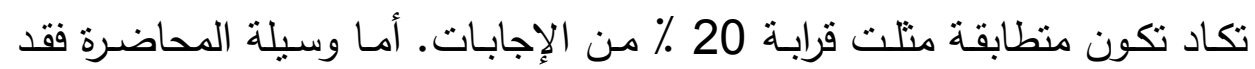
حصلت على 11 \% فقط من الإجابات. هناك علاقة ذات دلالة إحصائية ما بين

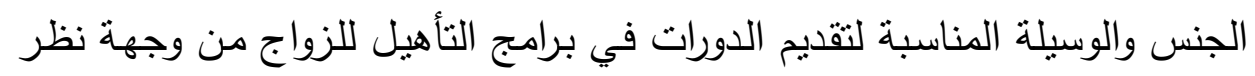

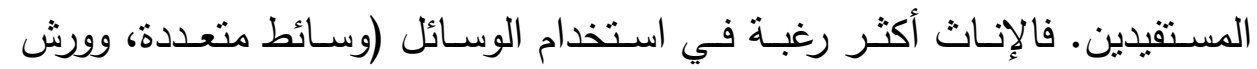
عمل، وتمـارين تطبيقيـة لمواضيع البرنـامج) أمـا الذكور فأكثر رغبـة في استخدام وسيلة (العرض التقديمي).

\section{ما يحفز الآخرين للالتحاق ببرامج التأهيل للزوج}

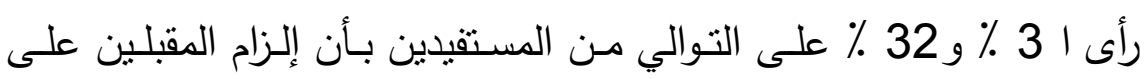
الزواج بالالتحاق ببرامج التأهيل للزواج ومعرفة النتائج الإيجابية لهذه البرامج هي

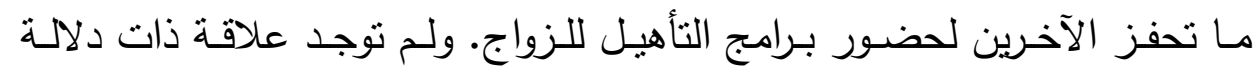

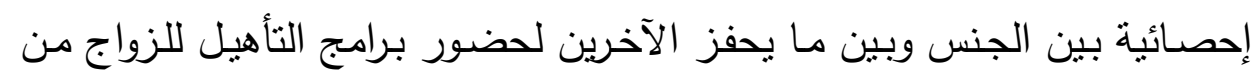


وجهة نظر المستقيدين.

مقدمو برامج التأهيل للزواج

اختار 37 ، 33 ، 33 ٪ من المستقيدين على التوالي: أن تكون لديهم خبرة في الاستشارات الزوجية والأسرية، أن يكونوا متخصصين علميًا في الإرشاد الزواجي لئي والأسري، أن يقدم كل منهم دورة واحدة فقط في البرنامج. وتوجد علاقة ذات دلالة إحصائية بين الجنس وبين ما يجب أن يتوفر في مقدمي برامج التأهيل للزواج من وند وجهة نظر المستقفيدين، نالت فيها الإنـاث النسـب المئويـة الأعلى في الاختيـار الثاني، وهو أن تكون لـى مقدمي بـرامج التأهيل للززواج خبرة في الاسنشـارات الزوجية والأسرية. (المكان

- موقع/مساحة المكان: بأن يسهل الوصول إليه، ويتسع لأعداد كبيرة.

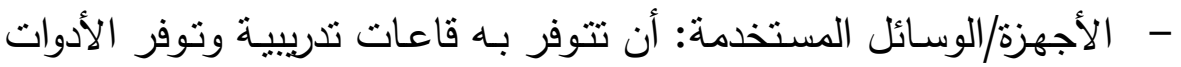
المناسبة لمحتوى الدورات منل (الطهي/التجميل).

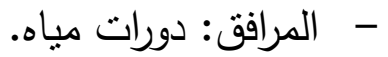

\section{توصيات الاراسة}

\section{توصيات الدراسة}

- تقديم برامج التأهيل للزواج للمقبلين على الزواج فقط، وتصميم برامج أخرى تخص العزاب، والمتزوجين، والمطلقين، والأرامل. - تقديم مقترح لوحدة الإرشاد الاجتماعي التابعة لوزارة الثؤون الاجتماعية،

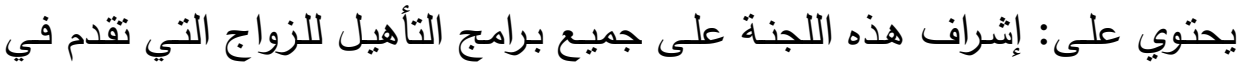

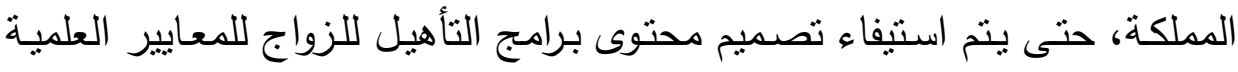


التي تم عرض فكرة عامـة عنها في الإطـار النظري للاراسـة. إضـافة إلى توحيد

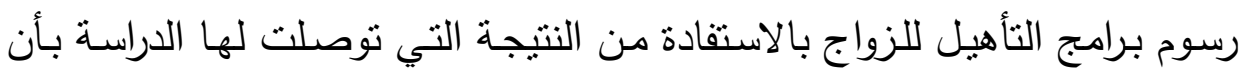
متوســ الرسـوم المناسـبة لهـذه البـرامج قــ تـراوح مــا بـين 460 - 600 ريال سعودي(1). وأخيرا وضع شروط ومعايير لمقدمي برامج ودورات التأهيل للزواج.

\section{شكــر و تقديـر}

شـكر لمركـز المـودة الاجتهـاعي للإصــلاح والتوجيـه الأسـري بجدة، جمعيـة الثـقائق، مركز نراتيـب للاستثمارات النفسية والتزبوية لتعاونهم في المرحلة الميدانية من الرسالة. شكر وتقدير لسعادة الدكتور إسماعيل قشقري على توجيهاته وملاحظاته القيمة.

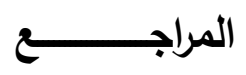

أولاً: المراجع العربية

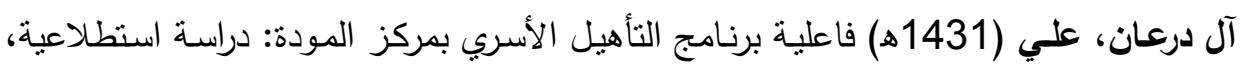

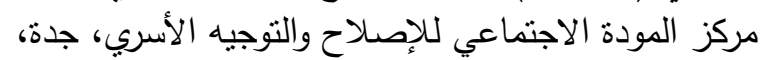

http://international.daralhayat.com/ print/134557

رجب، كريم وآخرون (2004م) تأثير التأهيل للزواج على نجاح الحياة الأسرية، مركز البحوث

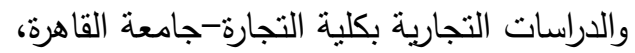

http://www.pathways.cu.edu.eg/news/news/uf/24186_10- B9_Projects.doc

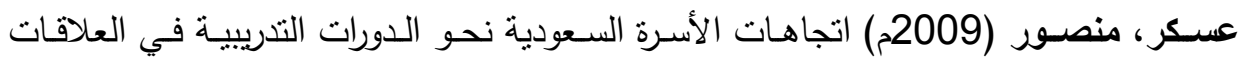

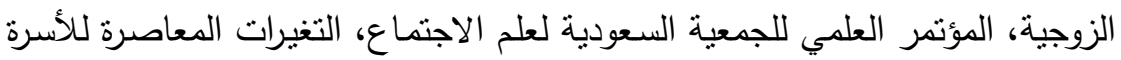

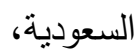
http://www.imamu.edu.sa/colleg_instt/colleg/sociology/saudi_jam3eya

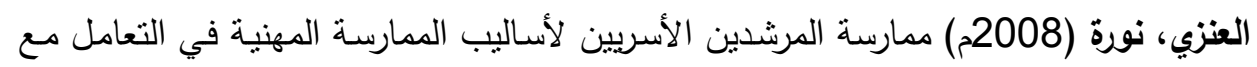

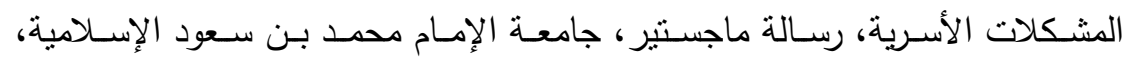

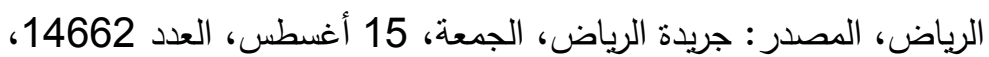
.http://www.alriyadh.com/2008/08/15/article367411.html غيث، عاطف (2002م) قاموس علم الاجتماع، الإسكندرية: دار المعرفة الجامعية. (1) وذلك باختلاف المستوى الاقتصادي لعينة الدراسة الحالية. 


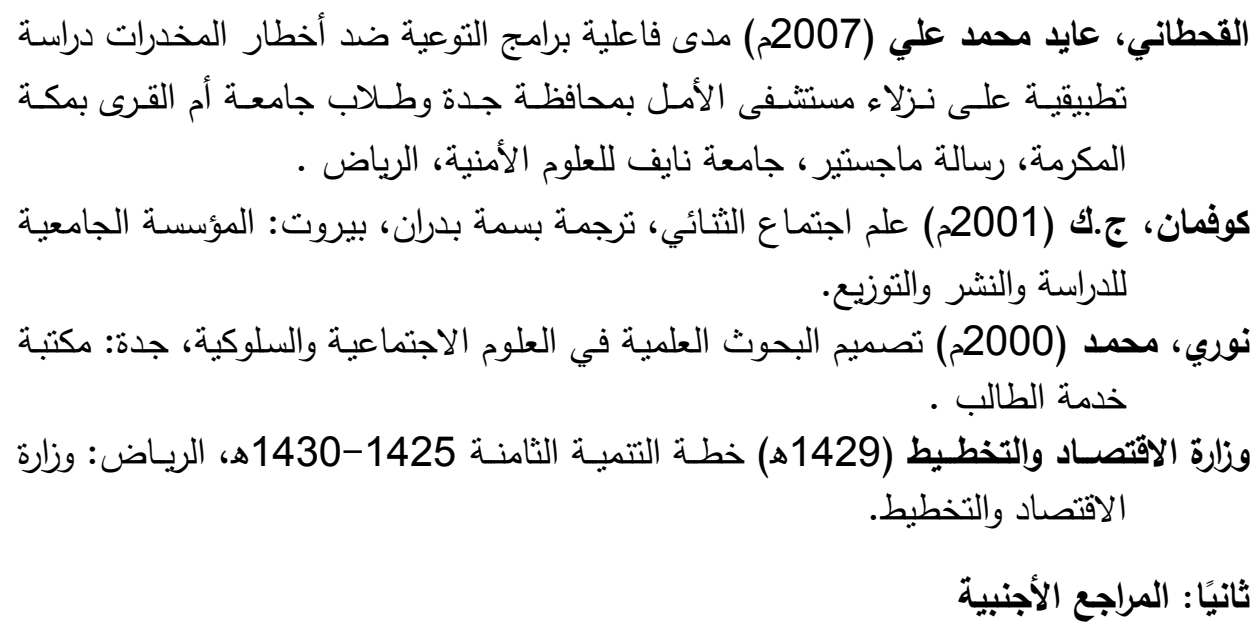

Balswick, Judith and Balswic, Jack (2007) Marriage Enrichment Program Evaluation, Family Ministry: Empowering Through Faith, http://www.fmef.org/pages/printable_page.cfm? PAGE_ID=86.

Blanchard, Victoria (April, 2008) Does Marriage and Relationship Education Improve Couples Communication? A Meta-Analytic Study, M. SC. Thesis, submitted to the factuality of Brigham Young University in Partial fulfillment of the requirements for the degree of Master of Since Department of Marriage Family and Human Development, Brigham Young Universitycontentdm.lib.byu.edu/ETD/image/etd2278.pdf.

Childs, Geniel (August, 2009) Marriage preparation education programs: an evaluation of essential elements of quality, M SC. Thesis, submitted to the faculty of Brigham Young University Master of Science School of Family Life, Brigham Young University, contentdm.lib.byu.edu/ ETD/ image/etd2983 .pdf.

Fawcett, Elizabeth (August, 2006) Is marriage education effective? a meta-analytic review of marriage education programs, D. SC. Thesis, A dissertation submitted to the faculty of Brigham Young University in partial fulfillment of the requirements for the degree of Doctor of Philosophy Department of Marriage, Family and Human Development, Brigham Young University. contentdm.lib.byu.edu/ETD/image/ etd2983.pdf.

Kefalas, Maria (Sept, 2005) Marriage is More than Being Together: The Meaning of Marriage among Young Adults in the United States, Network on Transitions to Adulthood Research Network, Working Paper, p.7. www.transad.pop. upenn.edu/downloads/kefalasmarriagenorms.pdf.

Knox, Virginia and Fein, David (May, 2005) Designing a Marriage Education Demonstration and Evaluation for Low-Income Married Couples.www.mdrc.org/publications/shm_guidelines.pdf.

Lamanna, Mary (2006) Marriages and Families: Making Choices In A Diverse Society, Sixth Edition, New Jersey: Wadsworth Publishing Company.

Ooms, Theodora (July 2005) The New Kid on The Block: What is Marriage Education and Does it Work? Center of Law and Social Policy, Couples and Marriage Series, Brief No 7.

Saleh, Dolah $(1430 \mathrm{H})$ The Planning of a Marriage, The next time someone admonishes you saying that you are "too picky," say "thank you" and appreciate the complement. http://www.dolah.net/docs/love/PlannmgofaMarriage.pdf, Viewed at 26/1/1430.

Snyder, Iliana (April, 2007) Assessing perceived marriage education needs and interests of latino individuals in Utah county, M. SC. Thesis, submitted to the faculty of, Brigham Young 


$$
\text { عبيد علي عطبان آل مظف و غبداء عبد الله الجوبسر }
$$

University, in partial fulfillment of the requirements for the degree of Master of Science Marriage and Family Therapy Program, Brigham Young University UTAH, contentdm.lib.byu.edu/ETD/image/etdl674.pdf. 


\title{
The Role of Guidance Programs in the Awareness of Planning for Marriage and Family Constructing "A Descriptive Analytical Study of Marital Preparation Programs and their Beneficiaries in Jeddah"
}

\author{
Obaid Ali Al-Modaf and Ghayda Abdullah Al-Juwaiser \\ Communication Skills Department, and Sociology \& Social Work \\ Department, King Abdulaziz University, Jeddah, Saudi Arabia
}

\begin{abstract}
Marriage is a "life-long project" and projects require planning. This study aimed at knowing the role of Marriage Preparation Programs (MPP) in the awareness of marriage planning through: their content, their used means, and the time allocated for lectures and activities. In addition, the study aimed at knowing the point of view of the beneficiaries of these programs about what has been presented and some of their socio-demographic characteristics. The current study is a descriptive study that used two tools to collect field data: a questionnaire to describe and analyze the programs' content and personal interviews with the beneficiaries of these programs. Four MPPprovided by three centers in Jeddah - and seventy-two cases: 32 females and 40 males were chosen through purposive sampling. The major findings of this study can be generalized as followed: I. Marriage goals, sex education, and dialogue between spouses are the most provided subjects by MPP. II. Lectures are the mostly used means to deliver MPPs' content. III. Differences exist between MPPs in terms of allocated time. IV. The most important subjects to be covered by MPP, from the beneficiaries' point of view, are: spouses' rights and duties, dialogue between spouses, the goal of marriage, dealing with anger, sex education, organizing the family budget, and the transference to the marital house. Generally speaking, MPP role in the awareness of marriage planning and family constructing was found to be limited. The study recommended the following: make the results of this research available for MPP providers; do more research in the field of MPP; provide MPP only for the beneficiaries who intend to marry; and design different types of marriage/family education programs for: non-married, married spouses, fathers and mothers, divorced, and widowed beneficiaries.
\end{abstract}


